\title{
The interaction of MC3R and MC4R with MRAP2, ACTH, $\alpha-M S H$ and AgRP in chickens
}

\author{
Jiannan Zhang, Xin Li, Yawei Zhou, Lin Cui, Jing Li, Chenlei Wu, Yiping Wan, \\ Juan Li and Yajun Wang
}

Key Laboratory of Bio-resources and Eco-environment of Ministry of Education, College of Life Sciences, Sichuan University, Chengdu, People's Republic of China
Correspondence should be addressed to $\mathrm{Y}$ Wang or $\mathrm{J} \mathrm{Li}$ Email cdwyjhk@gmail.com or lijuanscuhk@163.com

\begin{abstract}
The interaction of melanocortin-4 (MC4R) and melanocortin-3 (MC3R) receptors with proopiomelanocortin (POMC)-derived peptides (e.g. $\alpha-\mathrm{MSH})$, agouti-related protein (AgRP) and melanocortin-2 receptor accessory protein 2 (MRAP2) is suggested to play critical roles in energy balance of vertebrates. However, evidence on their interaction in birds remains scarce. Our study aims to reveal their interaction in chickens and the results showed that (1) chicken (c-)MC3R and CMC4R expressed in Chinese hamster ovary (CHO) cells can be activated by $\alpha-\mathrm{MSH}$ and $\mathrm{ACTH}_{1-39}$ equipotently, monitored by a pGL3CRE-luciferase reporter system; (2) CMC3R and CMC4R, when co-expressed with CMRAP2 (or CMRAP, a CMRAP2 homolog), show increased sensitivity to ACTH treatment and thus likely act as ACTH-preferring receptors, and the interaction between $\mathrm{CMC3R/CMC4R}$ and CMRAP2 was demonstrated by co-immunoprecipitation assay; (3) both CMC3R and CMC4R display constitutive activity when expressed in $\mathrm{CHO}$ cells, as monitored by dualluciferase reporter assay, and CMRAP2 (and CMRAP) can modulate their constitutive activity; (4) AgRP inhibits the constitutive activity of CMC3R/CMC4R, and it also antagonizes ACTH/ $\alpha-M S H$ action on $\mathrm{CMC} 4 \mathrm{R} / \mathrm{CMC} 3 \mathrm{R}$, indicating that AgRP functions as the inverse agonist and antagonist for both receptors. These findings, together with the co-expression of $C M C 4 R, C M C 3 R, C M R A P 2, C A g R P$ and $C P O M C$ in chicken hypothalamus detected by quantitative real-time PCR, suggest that within the hypothalamus, $\alpha-\mathrm{MSH} /$ $A C T H, A g R P$ and MRAP2 may interact at the MC4R(/MC3R) interface to control energy balance. Furthermore, our data provide novel proof for the involvement of MRAP2 (and MRAP) in fine-tuning the constitutive activity and ligand sensitivity and selectivity of both MC3R and MC4R in vertebrates.
\end{abstract}
Key Words
- chicken
- MC3R and MC4R
- MRAP2
- ACTH and $\alpha-\mathrm{MSH}$
- AgRP

Journal of Endocrinology (2017) 234, 155-174

\section{Introduction}

It is well documented that in mammals, proopiomelanocortin (POMC) gene encodes a large POMC precursor, and the tissue-specific processing of POMC precursor by two prohormone convertases (PC1/3 and PC2) gives rise to several structurally related melanocortin peptides, including adrenocorticotropin (ACTH), $\alpha$-melanocyte-stimulating hormone ( $\alpha$-MSH), $\beta$-MSH and $\gamma$-MSH (Cone 2006). In the anterior pituitary, POMC can generate ACTH of 39 amino acids $\left(\mathrm{ACTH}_{1-39}\right)$ via PC1/3 processing, while in the hypothalamus and intermediate

Published by Bioscientifica Ltd. 
lobe of the pituitary, POMC mainly yields $\alpha$-MSH via PC1/3 and PC2 processing (Cawley et al. 2016). These bioactive peptides exert diverse actions, such as regulation of skin pigmentation, adrenal gland function and energy balance, through interaction with 5 melanocortin receptors (MCR), namely MC1R, MC2R (also called ACTHR), MC3R, MC4R and MC5R respectively (Chhajlani \& Wikberg 1992, Mountjoy et al. 1992, Yaswen et al. 1999, Cone 2006). All these MCRs belong to G protein-coupled receptor (GPCR) and their activation can trigger multiple signaling pathways, including cAMP signaling pathway (Cone 2006, Ghamari-Langroudi et al. 2015).

Among the 5 MCRs studied in mammals, MC4R and MC3R and their ligand (i.e. $\alpha$-MSH) have attracted much attention due to their pivotal roles in the regulation of food intake, energy expenditure, body weight, metabolism and obesity (Krude et al. 1998, Cone 2006). It is clear that within the hypothalamus, $\alpha-\mathrm{MSH}$ derived from POMC neurons in the arcuate nucleus can bind to and activate MC3R and MC4R expressed in different hypothalamic nuclei and thus regulate energy balance (Roselli-Rehfuss et al. 1993, Mountjoy et al. 1994). Targeted disruption of MC4R causes hyperphagia, obesity, hyperinsulinemia and longitudinal growth in mice (Huszar et al. 1997). Similarly, inactivation of mouse MC3R causes an increase in fat mass and obesity (Butler et al. 2000, Chen et al. 2000). These findings emphasize the importance of MC4R/MC3R signaling in energy homeostasis. Apart from $\alpha$-MSH, agouti-related protein (AgRP), an endogenous antagonist of MC4R/MC3R, can also bind to MC4R/MC3R and control energy balance mainly via antagonizing $\alpha$-MSH actions (Fong et al. 1997, Ollmann et al. 1997, Rossi et al. 1998). Like $\alpha$-MSH, AgRP is highly expressed in the arcuate nucleus (Ollmann et al. 1997, Shutter et al. 1997), where it is mainly co-localized to neuropeptide Y (NPY) neurons (Hahn et al. 1998, Chen et al. 1999). Transgenic mice over-expressing AgRP recapitulate many features of MC4R-null mice, including obesity, increased body length and hyperinsulinemia (Graham et al. 1997, Ollmann et al. 1997). These findings also highlight the importance of the competitive interaction between $\alpha$ $\mathrm{MSH}$ and AgRP at the MC4R(/MC3R) interface to control energy balance. Recently, two melanocortin-2 receptor accessory proteins, named MRAP (also called MRAP1) and MRAP2, respectively, have been shown to modulate MCR functions (Metherell et al. 2005, Chan et al. 2009, Sebag \& Hinkle 2009a,b). For instance, MRAP2 can interact with MC4R and modulate MC4R-mediated cAMP signaling (Chan et al. 2009, Asai et al. 2013), while MRAP is crucial for MC2R trafficking, ACTH binding and signaling (Sebag \& Hinkle 2007, 2009b, Dores et al. 2016a). Mice with whole-body and brain-specific deletion of MRAP2 develop early-onset severe obesity, due to the impaired MC4R signaling (Asai et al. 2013). Taken together, all these findings outline a more complex interaction of MC4R (or $\mathrm{MC} 3 \mathrm{R})$ with $\alpha-\mathrm{MSH}, \mathrm{AgRP}$ and MRAP2 in the regulation of energy homeostasis.

As in mammals, the interaction of MC4R with $\alpha-\mathrm{MSH}$, AgRP and MRAP2 has also been suggested to play a critical role in energy balance in teleosts (Forlano \& Cone 2007, Cerda-Reverter et al. 2011, Sebag et al. 2013). In goldfish and rainbow trouts, i.c.v. injection of MC4R(/MC3R) agonist and antagonist can inhibit and stimulate food intake, respectively (Cerda-Reverter et al. 2003, Schjolden et al. 2009). Transgenic zebrafish over-expressing AgRP exhibit obesity and increased linear growth (Song \& Cone 2007, Zhang et al. 2012). Moreover, two MRAP2s, named MRAP2a and MRAP2b, have been identified in zebrafish (Agulleiro et al. 2010). MRAP2a is expressed at larval stage and stimulates growth of zebrafish by blocking the action of MC4R, while MRAP2b expressed at a later developmental stage enhances the responsiveness of MC4R to $\alpha-\mathrm{MSH}$, thus increasing its capacity for regulating food intake and growth (Sebag et al. 2013). In addition, an interesting study has shown that in the presence of MRAP2a, MC4R becomes an ACTH receptor, which may mediate ACTHinduced anorexic action (Josep Agulleiro et al. 2013). All these findings also depict an interaction network of MC4R with $\alpha-\mathrm{MSH} / \mathrm{ACTH}, \mathrm{AgRP}$ and MRAP2 involved in the control of energy balance and growth of teleosts.

As in mammals and teleosts, POMC, AgRP, MC4R, $M C 3 R$ and MRAP2 also exist in birds (Takeuchi \& Takahashi 1998, 1999, Takeuchi et al. 1999, 2000, Dores \& Lecaude 2005, Boswell \& Dunn 2015, Dores 2016, Ren et al. 2017). Central administration of $\alpha-\mathrm{MSH}$ or ACTH can inhibit food intake in chicks and ring doves (Kawakami et al. 2000, Strader et al. 2003, Cline et al. 2008, Shipp et al. 2015), while central injection of AgRP stimulates food intake or attenuates the anorexic action of $\alpha$-MSH (Tachibana et al. 2001, Strader et al. 2003). It is reported that both $P O M C$ and $A g R P$ are expressed in avian hypothalamic infundibular nucleus, a structure equivalent to mammalian arcuate nucleus, and food deprivation/ restriction can induce hypothalamic AgRP expression in chickens or quails (Boswell et al. 2002, PhillipsSingh et al. 2003, Dunn et al. 2013, 2015). These findings suggest that POMC-derived peptides ( $\alpha$-MSH/ACTH) and AgRP are likely involved in the control of avian 
energy balance, presumably through interaction with MC4R/MC3R expressed in the hypothalamus (Ling et al. 2004, Boswell \& Dunn 2015, Wang et al. 2016). However, there has been no direct evidence showing the complex interaction of MC4R(/MC3R) with $\alpha$-MSH/ACTH, AgRP and MRAP2 in birds prior to current report. Chicken is an animal model widely used for agricultural and biomedical research (Hen et al. 2006, Xu et al. 2016). Broiler chickens display rapid body weight gain, hyperphagia, ovarian dysfunction and other metabolic disorders, whereas layer chickens are lean with efficient egg production (Hen et al. 2006, Resnyk et al. 2013). These unique features render chickens an excellent model to decipher the conserved roles of $\mathrm{MC} 4 \mathrm{R}(/ \mathrm{MC} 3 \mathrm{R})$ signaling in energy balance, metabolism, growth and reproduction across vertebrates. Therefore, using chickens as the model, our present study aimed to investigate: (1) whether $\alpha$-MSH/ACTH and AgRP have opposite actions on MC4R/MC3R signaling; (2) whether MC4R/MC3R functions can be modulated by MRAP2 (or MRAP). As a result, we demonstrated that as in mammals/teleosts, $\alpha$-MSH/ACTH can activate MC4R and MC3R, while AgRP can antagonize $\alpha$-MSH/ACTH action on MC4R/MC3R and inhibit the constitutive activity of MC4R/MC3R. Strikingly, we also observed that MRAP2 can enhance the sensitivity of MC4R and MC3R for ACTH and block the constitutive activity of both receptors. These findings, together with the co-expression of $M C 4 R$, $M C 3 R, A g R P, P O M C$ and MRAP2 detected in chicken hypothalamus, suggest that within the hypothalamus, $\alpha-\mathrm{MSH} / \mathrm{ACTH}, \mathrm{AgRP}$ and MRAP2 may interact with $\mathrm{MC} 4 \mathrm{R} / \mathrm{MC} 3 \mathrm{R})$ to control energy balance in birds, as demonstrated in mammals/teleosts (Asai et al. 2013, Josep Agulleiro et al. 2013, Sebag et al. 2013). Meanwhile, the increased sensitivity of MC4R/MC3R for ACTH in the presence of MRAP2 also points out the possibility that in addition to being a key player in the pituitary-adrenal axis, ACTH may play a yet-appreciated role in energy balance via interaction with MC4R/MC3R in birds, and possibly in other vertebrates as well.

\section{Materials and methods}

\section{Chemicals, primers, peptides and antibodies}

All chemicals were purchased from Sigma-Aldrich and restriction enzymes were obtained from TaKaRa. Chicken (c-) $\mathrm{ACTH}_{1-39}, \alpha$-MSH (acetyl- $\left.\alpha-\mathrm{MSH}\right), \beta-\mathrm{MSH}$ and $\gamma$-MSH were synthesized by GL Biochem Ltd (Shanghai, China). The purity of synthesized peptides is more than $95 \%$ (analyzed by HPLC) and their structures were verified by mass spectrometry. Recombinant human AgRP protein (Cat no. 704-AG) was purchased from R\&D Systems. Anti-Flag Affinity Gel beads were purchased from BioTool company (BioTool, Shanghai, China). Rabbit anti-Myc polyclonal antibody was purchased from Abclonal Technology (Abclonal, Wuhan, China). Rabbit anti-Flag monoclonal antibody and mouse anti-Myc-monoclonal antibody were from Cell Signaling Technology. All primers used in this study were synthesized by Beijing Genome Institute (BGI, China) and listed in Supplementary Table 1 (see section on supplementary data given at the end of this article).

\section{Animals and tissues}

Adult chickens or chicks (Lohmann layer) of both sexes used in this study were purchased from a local commercial company. Chickens were killed and various tissues were collected, frozen in liquid nitrogen and stored at $-80^{\circ} \mathrm{C}$ until use. All animal experimental protocols used in this study were approved by the Animal Ethics Committee of College of Life Sciences, Sichuan University.

\section{Total RNA extraction and quantitative real-time PCR assays}

Total RNA was extracted from chicken tissues using RNAzol (Molecular Research Center, Cincinnati, OH, USA) and dissolved in DEPC-treated $\mathrm{H}_{2} \mathrm{O}$. These RNA samples were reversely transcribed by Moloney murine leukemia virus (MMLV) reverse transcriptase (Takara) and were either used for PCR amplification of target genes, or for quantitative real-time PCR assay of gene expression, as described in our previous study (Cai et al. 2015).

\section{Cloning of chicken MRAP2 CDNA}

Using human MRAP2 cDNA as a reference, we performed a search in the chicken genome database (http://www. ensembl.org/gallus_gallus) and identified a DNA fragment of MRAP2. According to this sequence information, gene-specific primers were designed to amplify the $5^{\prime}$ and 3'-cDNA ends of MRAP2 from chicken brain using SMART-RACE cDNA amplification kit (Clontech). The PCR product was cloned into PTA2 vector and sequenced by BGI. Finally, the full-length cDNA of $c M R A P 2$ was determined based on the sequences of 5'- and 3'-cDNA ends with an overlapping region.

Published by Bioscientifica Ltd. 
Functional analysis of chicken MC3R, MC4R, MC2R, MRAP and MRAP2

Based on the cloned cDNA sequences of chicken MRAP2 and MRAP, or the cDNA sequences of chicken melanocortin-2 receptor (cMC2R, NM_001031515), melanocortin-3 receptor (cMC3R, BAA32555.1) and melanocortin-4 receptor (cMC4R, BAA25252.1) published in previous studies (Takeuchi \& Takahashi 1998, 1999, Takeuchi et al. 1998), the coding regions of these genes were amplified by PCR with high-fidelity Taq DNA polymerase and cloned into pcDNA3.1(+) vector.

According to our established method (Wang et al. 2007, 2012), each receptor (cMC4R/cMC3R) transiently expressed in Chinese hamster ovary $(\mathrm{CHO})$ cells was treated by chicken $\mathrm{ACTH}_{1-39} / \alpha-\mathrm{MSH} / \beta$-MSH$/ \gamma$-MSH $\left(10^{-12}-10^{-6} \mathrm{M}\right.$, $6 \mathrm{~h}$ ), and the receptor-activated cAMP signaling pathway was then monitored by a pGL3-CRE-Luciferase reporter system, which is capable of monitoring receptor-mediated cAMP production (Wang et al. 2007, 2012).

To test whether cMRAP2 and its homolog, cMRAP, could alter the pharmacological property of cMC3R/cMC4R (cMC2R used as a control), CHO cells co-transfected with cMRAP2 (or cMRAP) and receptor expression plasmids (at a ratio of 5:1, w/w) were treated by chicken $\mathrm{ACTH}_{1-39}$ or $\alpha-\mathrm{MSH}$, the relative potencies of the two peptides in activating these receptors were evaluated by the same reporter system.

\section{Co-immunoprecipitation (Co-IP) assay}

To investigate the interaction of chicken MC3R/MC4R with MRAP2, we first prepared the pcDNA3.1(+) expression plasmids encoding an N-terminally Myc-tagged MRAP2 (Myc-MRAP2) and N-/C-terminally Flag-tagged receptors by PCR. These MRAP2 and receptor expression plasmids were used to co-transfect $\mathrm{CHO}$ cells cultured in a $60-\mathrm{mm}$ dish (Nunc, Rochester, NY, USA) at $37^{\circ} \mathrm{C}$ by jetPRIME transfection reagent according to the manufacturer's instruction (Polyplus transfection, France). After $24 \mathrm{~h}$ of transfection, $\mathrm{CHO}$ cells were lysed for $30 \mathrm{~min}$ on ice in a lysis buffer (containing $0.1 \%$ n-dodecyl- $\beta$-maltoside and protease inhibitors). The cell lysates were centrifuged at $9600 \mathrm{~g}$ for $10 \mathrm{~min}$ at $4^{\circ} \mathrm{C}$ and supernatants were used either for Western blot, or Co-IP assay. For Co-IP, the cell lysates were added to anti-Flag Affinity Gel beads and incubated overnight at $4^{\circ} \mathrm{C}$. After incubation, the agarose beads were washed with lysis buffer, the supernatant was removed and $2 \times$ Laemmli sample buffer was added. After boiling for $5 \mathrm{~min}$, samples were run in SDS-polyacrylamide gel and rabbit anti-Myc antibodies (1:2000) were used for Western blot.

\section{Immunofluorescence microscopy}

$\mathrm{CHO}$ cells grown in a 24-well plate were co-transfected with Flag-cMC3R (or Flag-cMC4R) and Myc-cMRAP2 expression plasmids. After $24 \mathrm{~h}$ of transfection, cells were fixed by $4 \%$ paraformaldehyde, washed with PBS and blocked by $3 \%$ BSA and 10\% donkey serum in PBS for $45 \mathrm{~min}$. After blocking, cells were incubated with rabbit anti-Flag (1:200) and mouse anti-c-Myc antibodies (1:200) overnight at $4^{\circ} \mathrm{C}$. Primary antibodies were detected by goat anti-rabbit secondary antibodies coupled to Alexa-Fluor 488 or goat anti-mouse secondary antibodies (1:500) coupled to Alexa-Fluor 594 (Invitrogen). Cells were washed with PBS and stained by DAPI for $1 \mathrm{~min}$. The fluorescence was then examined by a Laser-scanning confocal microscope (LeicaTCS SP5 II).

\section{Detection of the basal constitutive activity of CMC3R and $\mathrm{CMC} 4 \mathrm{R}$}

The basal constitutive activity of cMC3R and cMC4R expressed in $\mathrm{CHO}$ cells was detected by dual-luciferase reporter assay, established in our previous studies (He et al. 2016, Gao et al. 2017). In brief, CHO cells were cultured in a 48 -well plate at a density of $1 \times 10^{5}$ cells per well before transfection. After $24 \mathrm{~h}$ of incubation, a mixture containing $480 \mathrm{ng}$ of pGL3-CRE-luciferase reporter construct (which is capable of monitoring receptorstimulated cAMP production), $5 \mathrm{ng}$ of pRL-TK construct (used to normalize transfection efficiency), $120 \mathrm{ng}$ of cMC3R/cMC4R expression plasmid, various amounts (0-600 ng) of cMRAP2 (or cMRAP) expression plasmid and $0.5 \mu \mathrm{L}$ of JetPRIME reagent, was prepared in transfection buffer and used to transfect $\mathrm{CHO}$ cells, following the manufacturer's instructions. $24 \mathrm{~h}$ later, culture medium was removed and $150 \mu \mathrm{L} 1 \times$ passive lysis buffer (Promega) was added to each well. Luciferase activities of $15 \mu \mathrm{L}$ cellular lysates were measured by using Dual-Luciferase Reporter Assay Kit (Promega). The cells transfected with empty pcDNA3.1(+) vector or the expression plasmid encoding chicken neuropeptide $S$ receptor (NPSR, a Gs protein-coupled receptor characterized in our laboratory: Fang \& Wang, unpublished observations) were used as controls. Luciferase activity of $\mathrm{CHO}$ cells expressing cMC4R/cMC3R was normalized to Renilla luciferase activity derived from the pRL-TK vector and then expressed as relative fold increase as compared

Published by Bioscientifica Ltd. 
with the control (CHO cells transfected with the empty pcDNA3.1(+) vector).

\section{Detection of the inverse agonistic and antagonistic actions of AgRP}

To evaluate whether AgRP could act as an inverse agonist to inhibit the basal constitutive activity of cMC3R/cMC4R, or act as an antagonist to block $\alpha-\mathrm{MSH} / \mathrm{ACTH}$ action on cMC3R/cMC4R activation, $\mathrm{CHO}$ cells transfected with cMC3R/cMC4R expression plasmid, or co-transfected with cMC3R/cMC4R and cMRAP2/cMRAP expression plasmid (at a ratio of 1:5), were treated by recombinant human AgRP $\left(10^{-12}-10^{-7} \mathrm{M}, 6 \mathrm{~h}\right)$ alone, or co-treated by both AgRP $\left(10^{-10}-10^{-7} \mathrm{M}\right)$ and chicken $\alpha$-MSH/ACTH $(10 \mathrm{nM})$. Then, the receptor-mediated cAMP production was monitored by pGL3-CRE-luciferase reporter system.

\section{Detection of cell surface expression of $C M C 2 R, C M C 3 R$ and CMC4R by ELISA}

To investigate whether CMRAP2 (or cMRAP) can alter the cell surface expression of cMC3R/cMC4R (cMC2R used as a control), the expression of Flag-cMC3R, Flag-cMC4R and Flag-cMC2R on cell membrane were measured by cell surface enzyme-linked immunosorbent assay (ELISA). In brief, $\mathrm{CHO}$ cells cultured in a 24-well plate were transfected with receptor expression plasmid or co-transfected with receptor and cMRAP2/cMRAP expression plasmids (at a ratio of 1:5). After $24 \mathrm{~h}$ of transfection, cells were fixed by $4 \%$ paraformaldehyde, washed with PBS and incubated with $5 \%$ milk in PBS for $45 \mathrm{~min}$ to block non-specific binding. These cells were incubated with rabbit antiFlag antibody (diluted 1:5000) in 5\% milk in PBS for $1 \mathrm{~h}$, washed with PBS and incubated with HRP-conjugated goat anti-rabbit secondary antibody (1:5000) for $1 \mathrm{~h}$. Finally, $\mathrm{CHO}$ cells were washed with PBS and incubated with the substrate $3,5,3^{\prime}, 5^{\prime}$-tetramethylbenzidine for $15 \mathrm{~min}$, and the reaction was stopped by adding an equal volume of $10 \%$ sulphuric acid. The absorbance was measured at $450 \mathrm{~nm}\left(\mathrm{OD}_{450}\right)$ on a Tri-Star LB 941 Multimode Reader (Berthold, Germany). Total expression of Flag-tagged receptor was measured by the same protocol, except the cells were permeabilized by $1 \%$ Triton X-100 in the blocking buffer. Absorbance of $\mathrm{CHO}$ cells transfected with empty pcDNA3.1 (+) vector was used to subtract the background. Finally, the surface expression was first calculated as the ratio to that of total expression of each receptor, and then expressed as the percentage of the control group ( $\mathrm{CHO}$ cells expressing cMC3R/cMC4R/ cMC2R only).

\section{Investigate the effect of fasting on AgRP, POMC, MRAP2 and NPY mRNA expression}

In this experiment, chicks (Lohmann layer, 4 week old) were maintained at $22^{\circ} \mathrm{C}$ on a 14 -h light, 10-h dark (14L:10D) photoperiod and fed a commercial mixed diet with free access to water. To determine whether fasting can regulate mRNA expression of $A g R P$ (NM_001031457), POMC (NM_001031098), MRAP2 and NPY (NM_205473) in the hypothalamus, 4-week-old male chicks of similar body weight were randomly divided into three groups: two experimental groups (8 individuals in each group) and one control group (8 individuals). In the experimental groups, chicks had free access to water but were deprived of food for $24 \mathrm{~h}$ or $36 \mathrm{~h}$. In the control group, all chicks had free access to food and water for $36 \mathrm{~h}$. At the end of the experiments, the hypothalamus from all chicks was collected to examine the mRNA levels of target genes by quantitative real-time PCR assay.

\section{Data analysis}

The mRNA level of each gene was first normalized by that of $\beta$-actin and then expressed as fold difference compared to control group or chosen tissues. The gene expression data or the reporter assay data were analyzed by one-way ANOVA followed by Dunnett's test. The dose-response curves were constructed using nonlinear regression models, and the corresponding half-maximal effective concentration $\left(\mathrm{EC}_{50}\right)$ values were evaluated with GraphPad Prism 5 (GraphPad Software). All experiments were repeated at least twice to validate our results.

\section{Results}

Chicken MC3R and MC4R can be activated by $\alpha-M S H$ and ACTH equipotently

To examine the relative potencies of chicken $\alpha-\mathrm{MSH}$, $\beta$-MSH, $\gamma$-MSH and $\mathrm{ACTH}_{1-39}$ in activating chicken MC3R and MC4R, each receptor was transiently expressed in $\mathrm{CHO}$ cells and treated by synthetic chicken peptides (Fig. 1). Receptor activation was then monitored by a pGL3-CRE-luciferase reporter system established in our laboratory (Wang et al. 2007, 2012), which is capable of monitoring receptor-induced cAMP production.
๑) 2017 Society for Endocrinology Printed in Great Britain 
A
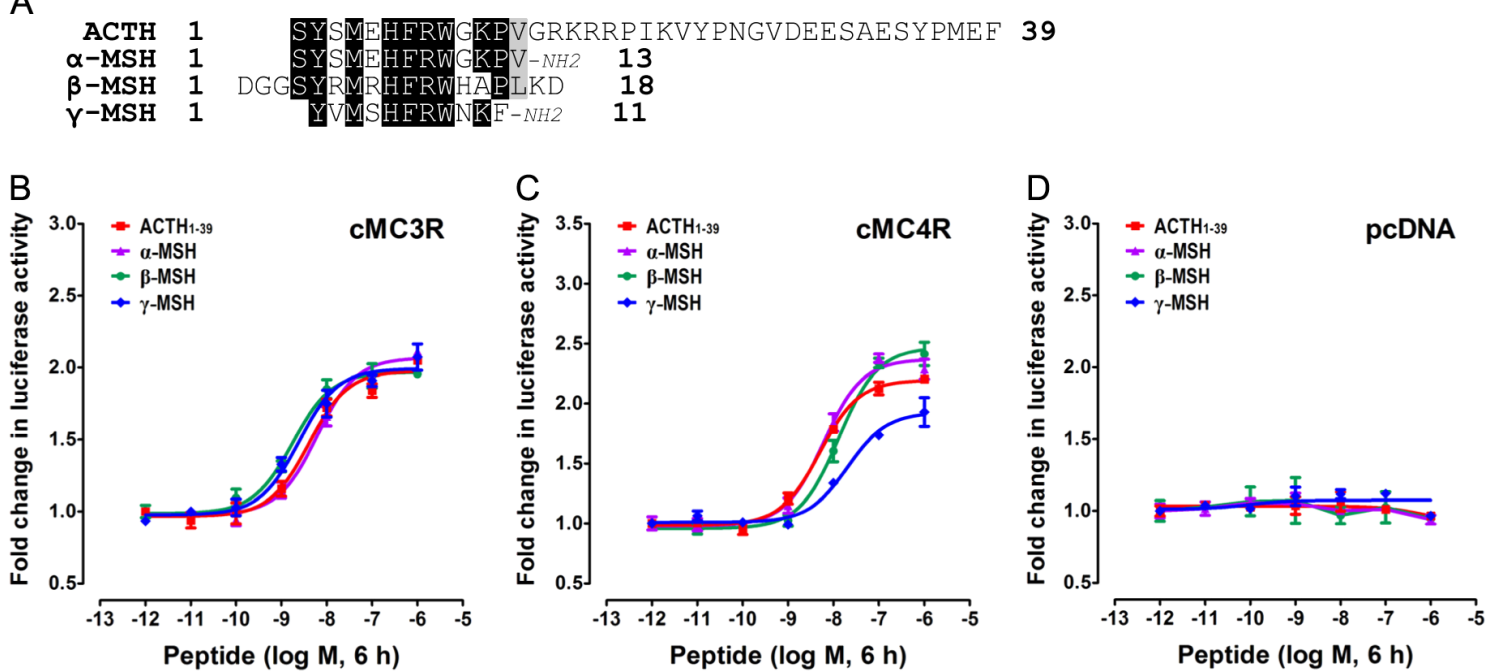

Figure 1

Functional analysis of chicken MC3R and MC4R. (A) Amino acid sequences of chicken ACTH ${ }_{1-39}, \alpha-M S H$ (acetyl- $\alpha-M S H$ with an amidated C-terminus), $\beta$-MSH and $\gamma$-MSH (with amidated C-terminus) used in this study. (B, C) Effects of chicken ACTH ${ }_{1-39}, \alpha-\mathrm{MSH}, \beta$-MSH and $\gamma$-MSH (10-12-10-6 M) in activating CMC3R (B) and CMC4R (C) expressed in CHO cells, as monitored by a pGL3-CRE-luciferase reporter system. (D) As a negative control, CHO cells transfected with the empty pcDNA3.1 (+) vector showed no response to peptide treatment. Each data point represents the mean \pm S.E.M. of 3 replicates $(N=3)$. A full colour version of this figure is available at http://dx.doi.org/10.1530/JOE-17-0131.

As shown in Fig. 1, all peptides could stimulate luciferase activities of $\mathrm{CHO}$ cells expressing cMC3R dose dependently. Since the $\mathrm{EC}_{50}$ values of all peptides tested $(\alpha-\mathrm{MSH}: 3.59 \pm 1.01 \mathrm{nM}$; АCTH: $4.29 \pm 1.22 \mathrm{nM} ; \beta-\mathrm{MSH}$ : $1.78 \pm 0.43 \mathrm{nM} ; \gamma$-MSH: $2.43 \pm 0.78 \mathrm{nM})$ are within the nanomolar range, it suggests that they may act as the endogenous ligands for cMC3R.

Like cMC3R, cMC4R could also be activated by $\alpha$-MSH $\left(\mathrm{EC}_{50}: 4.01 \pm 0.75 \mathrm{nM}\right)$ and $\mathrm{ACTH}_{1-39}$ $(5.34 \pm 1.21 \mathrm{nM})$ with similarly high potencies (Fig. 1). Although $\beta$-MSH and $\gamma$-MSH could also activate cMC4R, their potencies are 3- to 5-fold lower ( $\beta$-MSH: $13.34 \pm 2.33 \mathrm{nM} ; \gamma$-MSH: $20.31 \pm 4.73 \mathrm{nM}$ ) than those of $\alpha$-MSH/ACTH (Supplementary Table 2).

\section{Cloning of chicken MRAP2}

To examine whether chicken MRAP2 could interact with cMC4R/cMC3R in vitro, we first cloned the full-length CDNA of MRAP2 from chicken brain using RACE PCR. The cloned $c M R A P 2$ cDNA consists of 7 exons (accession no.: KX447647) and is predicted to encode a protein of 206 amino acids (KT183012) (Supplementary Fig. 1). Sequence alignment revealed that chicken MRAP2 shares high amino acid sequence identity with that of humans (74\%), Xenopus tropicalis (63\%) and zebrafish (MRAP2a, 48\%; MRAP2b, 45\%), and a comparatively low identity (24-30\%) with MRAP of chickens, Xenopus tropicalis, zebrafish, and mice (Fig. 2). Like human MRAP2, chicken MRAP2 contains a transmembrane domain, a putative glycosylation site $\left(\mathrm{Asn}^{9}\right)$ at the N-terminus, a putative domain (LKAHKYS) crucial for the formation of antiparallel homodimers (Sebag \& Hinkle 2009b), and a long C-terminal tail with many conserved residues (or regions) observed among vertebrates (Fig. 2). However, chicken MRAP2 lacks the typical 'LDYI' motif present in mouse MRAP, which is required for ACTH binding (Sebag $\&$ Hinkle 2009b).

\section{CMC4R and CMC3R can be preferentially activated by ACTH in the presence of CMRAP2}

To test whether chicken MRAP2 (or MRAP) could alter the responsiveness of cMC3R and $\mathrm{CMC} 4 \mathrm{R}$ to ACTH and $\alpha$-MSH, CHO cells co-expressing receptor and cMRAP2 (or cMRAP) were treated by $\mathrm{ACTH}_{1-39}$ and $\alpha-\mathrm{MSH}$, and the receptor activation was monitored by a pGL3-CREluciferase reporter system.

As shown in Fig. 3, in the presence of cMRAP2, both cMC3R and cMC4R could be preferentially activated by chicken $\mathrm{ACTH}_{1-39}$, and the potencies of $\mathrm{ACTH}_{1-39}$ in activating cMC3R and cMC4R increase $\sim 9$-fold and 21-fold, respectively, as indicated by the significant changes in $\mathrm{EC}_{50}$ values of $\mathrm{ACTH}_{1-39}$ from nanomolar to subnanomolar ranges (Fig. 3 and Table 1). Likewise, in the presence of cMRAP, both cMC3R and cMC4R could also 
CMRAP2 hUMRAP2 XMRAP2

z IMRAP $2 a$

$z$ IMRAP $2 b$

CMRAP

XMRAP

Z IMRAP

MMRAP

CMRAP2
hUMRAP2
xMRAP2
z IMRAP2a
z IMRAP2b
CMRAP
XMRAP
z IMRAP
MMRAP

CMRAP2

hUMRAP2

XMRAP2

z FMRAP2a

z IMRAP $2 b$

CMRAP

XMRAP

ZMRAP

MMRAP

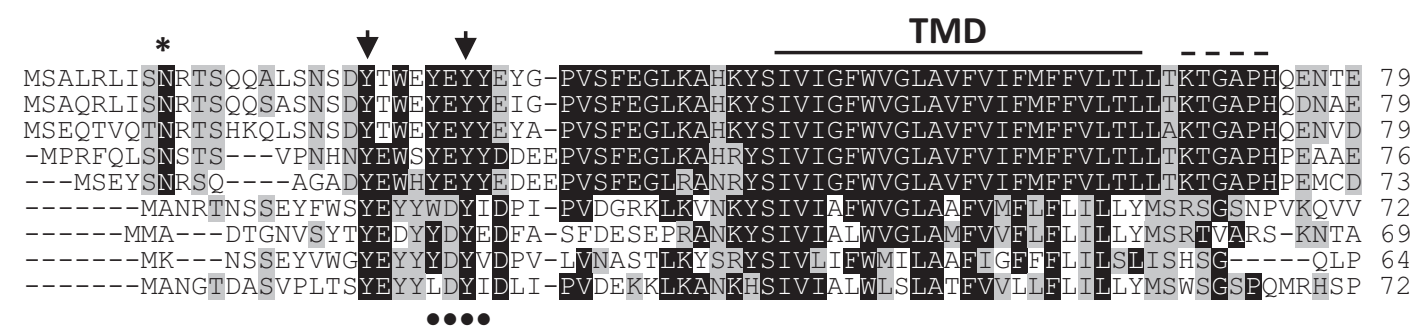

Long C-terminal tail
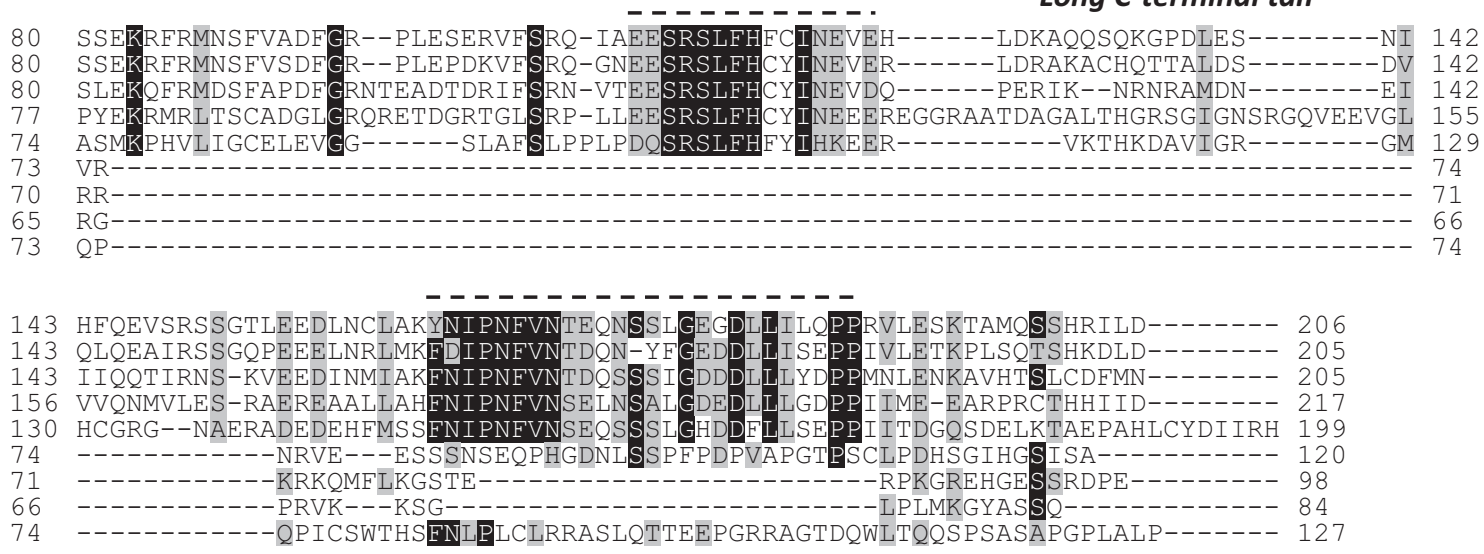

Figure 2

Amino acid alignment of chicken MRAP2 (cMRAP2, KT183012) with that of humans (hMRAP2, NP_612418), Xenopus tropicalis (xMRAP2, XP_002933963), zebrafish (zfMRAP2a, F8W4H9.1; zfMRAP2b, P0DM64), or with MRAP of chickens (cMRAP), Xenopus tropicalis (xMRAP, XP_002938489), zebrafish (zfMRAP, BC122349) and mice (mMRAP, NP_084120). The horizontal line marks the transmembrane domain (TMD). The asterisk indicates a potential $\mathrm{N}$-glycosylation site; Dots indicate the 'LDYI' motif presented in mouse MRAP, which is crucial for ACTH activation of MC2R (Sebag \& Hinkle 2009b). Triangles denote the domain (LKAHKYS) required for the formation of antiparallel MRAP2 homodimer (Sebag \& Hinkle 2009b). The conserved regions and amino acid residues noted in the long C-termini of vertebrate MRAP2 are indicated by horizontal dashed lines and black boxes respectively. Arrows indicate the two tyrosine $(\mathrm{Y})$ residues fully conserved in MRAPs across vertebrates. Dashes denote gaps in the alignment.

be preferentially activated by $\mathrm{ACTH}_{1-39}$, and the potencies of $\mathrm{ACTH}_{1-39}$ in activating both receptors increase $\sim 7$-fold. In sharp contrast, cMRAP2 (or cMRAP) causes a slight increase $(<2.3$-fold $)$ or no increase in the potencies of $\alpha$ $\mathrm{MSH}$ in activating cMC3R/cMC4R (Table 1). These findings indicate that in the presence of MRAP2 (or MRAP), both cMC3R and cMC4R show increased sensitivity and selectivity towards ACTH, and thus likely act as two ACTH-preferring receptors.

In contrast to cMC4R/cMC3R, cMC2R could only be activated by $\mathrm{ACTH}_{1-39}\left(\mathrm{EC}_{50}: 0.89 \pm 0.05 \mathrm{nM}\right)$ potently in the presence of cMRAP, but not MRAP2 (Fig. 3 and Table 1), indicating that cMC2R acts as an ACTH-specific receptor, as previously reported (Barlock et al. 2014).

Since cMRAP2 is more effective than cMRAP in enhancing the sensitivity of $\mathrm{cMC} 4 \mathrm{R}$ and $\mathrm{cMC} 3 \mathrm{R}$ for ACTH (Fig. 3 and Table 1), we further examined whether cMRAP2 could interact with cMC4R/cMC3R in vitro. Using double-fluorescence staining, we observed that Myc-cMRAP2 and Flag-cMC4R (or Flag-cMC3R) expressed in $\mathrm{CHO}$ cells were co-localized on the cell surface (Fig. 4). Co-immunoprecipitation assay further elucidates a direct interaction of Myc-cMRAP2 with cMC3R-Flag/cMC4R-Flag (Fig. 4). Although cMRAP is less effective than cMRAP2 in enhancing sensitivity of cMC4R/cMC3R for ACTH, Co-IP assay still showed that cMRAP could interact with cMC3R/cMC4R in vitro (data not shown).

\section{Chicken MRAP2 (and MRAP) can modulate the constitutive activity of CMC4R/cMC3R}

To test whether cMC4R/cMC3R displays constitutive activity similar to mammalian MC4R (Ollmann et al. 1997, Nijenhuis et al. 2001), we examined the basal luciferase activity of $\mathrm{CHO}$ cells expressing cMC4R or cMC3R using dual-luciferase reporter assay. As shown in Fig. 5, the basal luciferase activity of $\mathrm{CHO}$ cells expressing cMC3R is $\sim 3$-fold higher compared to that of cells transfected with the empty pcDNA3.1(+) vector. In contrast, CHO cells expressing chicken NPSR, a Gs protein-coupled receptor, display no basal activity under the same condition. http://joe.endocrinology-journals.org DOI: 10.1530/JOE-17-0131
○ 2017 Society for Endocrinology Printed in Great Britain 
A

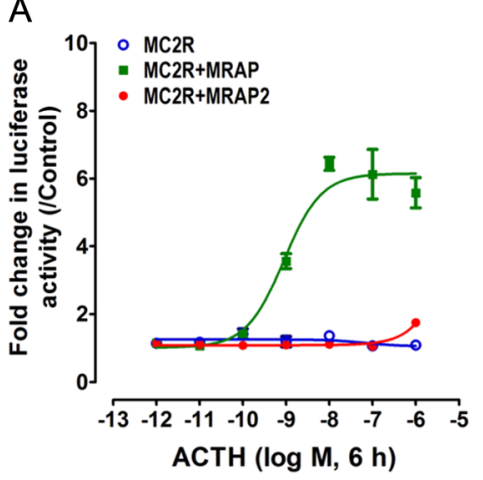

D

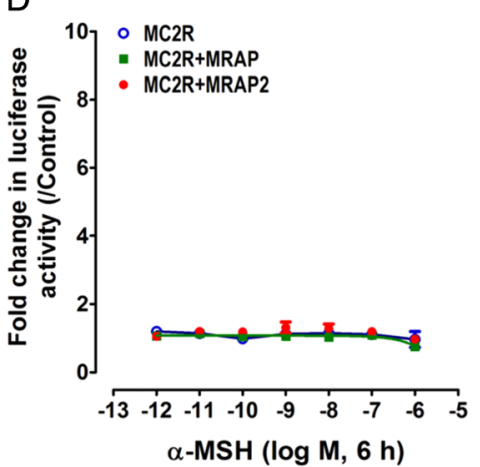

B

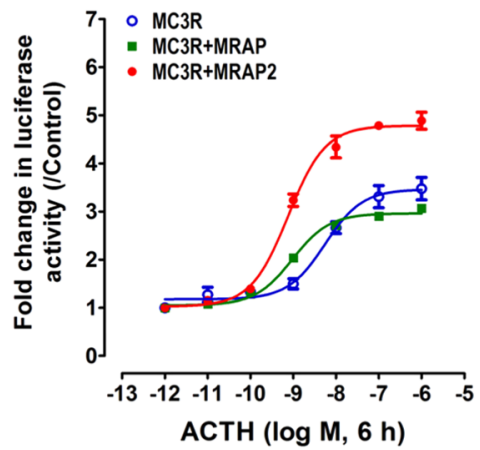

E

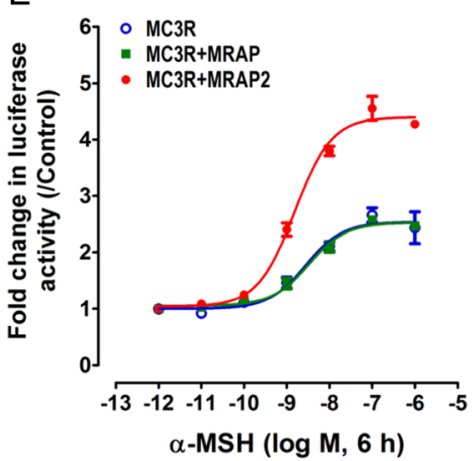

C

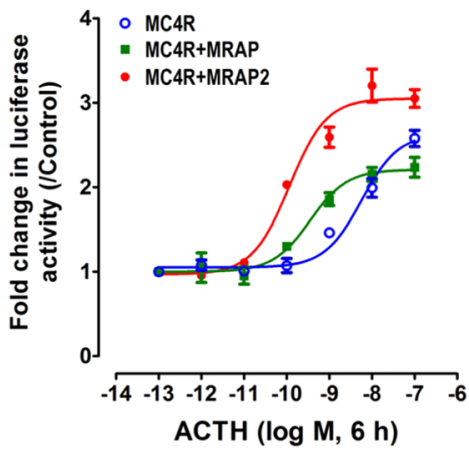

$\mathrm{F}$

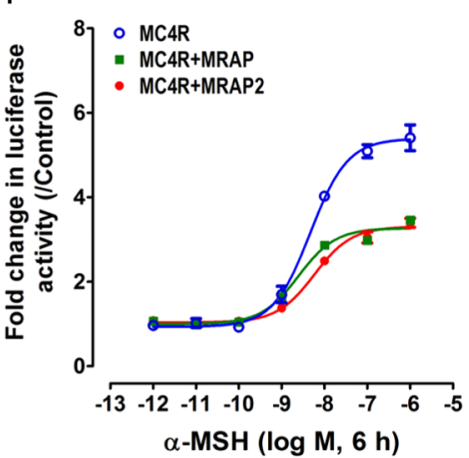

Figure 3

(A, B and C) Effects of ACTH ${ }_{1-39}$ in activating chicken MC2R (A), MC3R (B) and MC4R (C) expressed in CHO cells co-transfected with (or without) MRAP2/ MRAP expression plasmid, monitored by a pGL3-CRE-luciferase reporter system. (D, E and F) Effects of $\alpha$-MSH in activating chicken MC2R (D), MC3R (E) and MC4R (F) expressed in CHO cells co-transfected with (or without) MRAP2/MRAP, monitored by a pGL3-CRE-luciferase reporter system. Each data point represents the mean \pm S.E.M. of 3 replicates $(N=3)$. A full colour version of this figure is available at http://dx.doi.org/10.1530/JOE-17-0131.

Likewise, the basal luciferase activity of $\mathrm{CHO}$ cells expressing cMC4R is slightly, but significantly, higher $(\sim 1.4$ fold $)$ than that of control. These findings indicate

Table $1 \quad \mathrm{EC}_{50}$ values of chicken $\alpha-\mathrm{MSH} / \mathrm{ACTH}$ in activating CMC3R/cMC4R/cMC2R expressed in $\mathrm{CHO}$ cells, in the absence or presence of CMRAP2/CMRAP.

\begin{tabular}{|c|c|c|c|}
\hline \multicolumn{4}{|c|}{$\mathrm{EC}_{50}(\mathrm{nM})$} \\
\hline & cMC3R & cMC3R + cMRAP & cMC3R + cMRAP2 \\
\hline$\alpha-\mathrm{MSH}$ & $3.59 \pm 1.01$ & $3.26 \pm 0.65$ & $1.55 \pm 0.24$ \\
\hline $\mathrm{ACTH}_{1-39}$ & $4.29 \pm 1.22$ & $0.55 \pm 0.39 *$ & $0.47 \pm 0.28 *$ \\
\hline AgRP & $\begin{array}{l}3.62 \pm 1.04 \\
\text { CMC4R }\end{array}$ & $\begin{array}{c}9.61 \pm 5.12 \\
\text { CMC4R + CMRAP }\end{array}$ & $\begin{array}{c}- \\
\mathrm{CMC} 4 \mathrm{R}+\mathrm{CMRAP2}\end{array}$ \\
\hline$\alpha-\mathrm{MSH}$ & $4.01 \pm 0.75$ & $2.42 \pm 0.06 *$ & $3.96 \pm 1.79$ \\
\hline $\mathrm{ACTH}_{1-39}$ & $5.34 \pm 1.21$ & $0.74 \pm 0.24 *$ & $0.25 \pm 0.21 *$ \\
\hline AgRP & $\begin{array}{c}- \\
\mathrm{CMC} 2 \mathrm{R}\end{array}$ & $\begin{array}{c}- \\
\mathrm{CMC} 2 \mathrm{R}+\mathrm{CMRAP}\end{array}$ & $\begin{array}{c}- \\
\mathrm{CMC} 2 \mathrm{R}+\mathrm{CMRAP} 2\end{array}$ \\
\hline$\alpha-\mathrm{MSH}$ & $\mathrm{n}$ & $\mathrm{n}$ & $\mathrm{n}$ \\
\hline $\mathrm{ACTH}_{1-39}$ & $\mathrm{n}$ & $0.89 \pm 0.05$ & - \\
\hline
\end{tabular}

Data shown are the mean \pm S.E.M. of two to five independent experiments performed in triplicate. $\mathrm{EC}_{50}$ values of human AgRP in inhibiting the constitutive activity of CMC3R/cMC4R are also shown above.

$* P<0.05$ vs. CMC4R/cMC3R (analyzed by the Student $t$-test using GraphPad Prism 5 software). '-' indicates that $\mathrm{EC}_{50}$ values could not be estimated based on the experimental data; ' $n$ ' indicates no response. that both cMC3R and cMC4R are constitutively active receptors (Fig. 5).

Using dual-luciferase reporter assay, we further examined whether cMRAP2 (or cMRAP) could modulate the basal constitutive activity of cMC4R/cMC3R. As shown in Fig. 5, cMRAP2 could dose dependently inhibit the basal constitutive activity of cMC3R, when co-transfected, and the maximal inhibition was observed at the ratio of 1:5 (cMC3R:cMRAP2) plasmids used. In contrast, cMRAP has no significant effect on the basal activity of cMC3R. Although the constitutive activity of cMC4R is relatively weak, cMRAP2 could still reduce its basal constitutive activity significantly. Interestingly, unlike cMRAP2, cMRAP could enhance the basal constitutive activity of cMC4R in a dose-dependent manner.

To determine whether the suppressed (or enhanced) basal constitutive activity of cMC3R or cMC4R is due to alterations in their cell surface expression, surface expression of Flag-cMC3R/Flag-cMC4R in CHO cells was examined by whole-cell ELISA assay. As shown in Fig. 6, co-expression of cMRAP2 (or cMRAP) with cMC3R did not alter surface expression of cMC3R significantly,

Published by Bioscientifica Ltd. 
A

$\operatorname{MC3R}$

MC4R
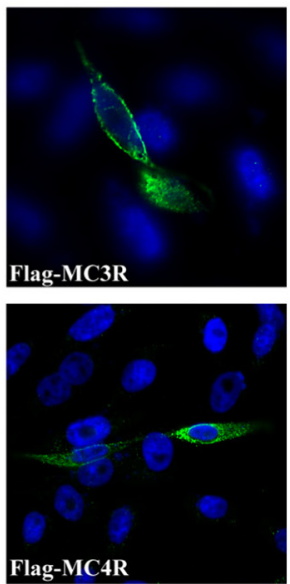
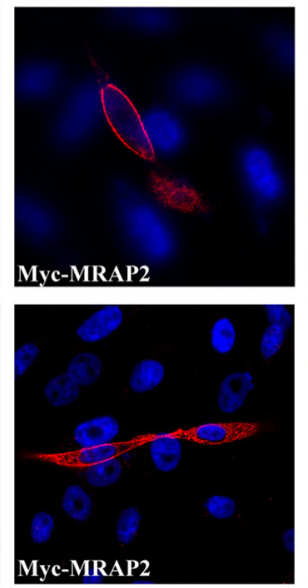
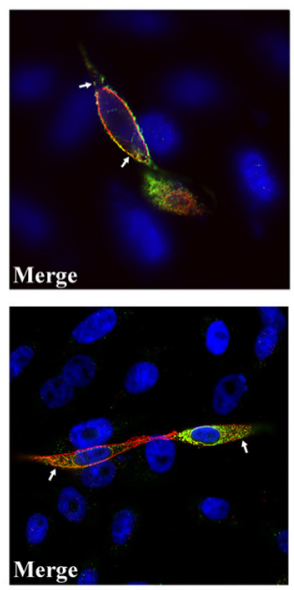

B

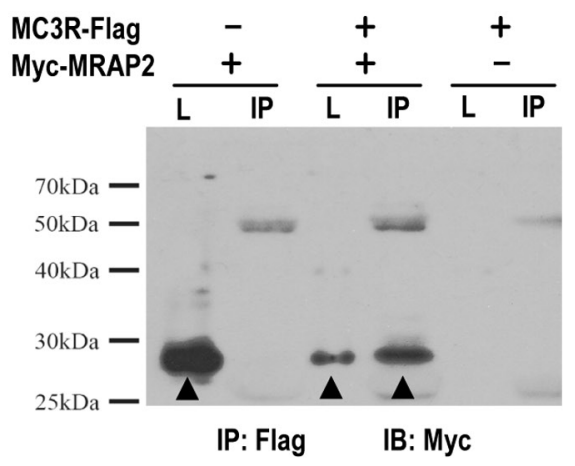

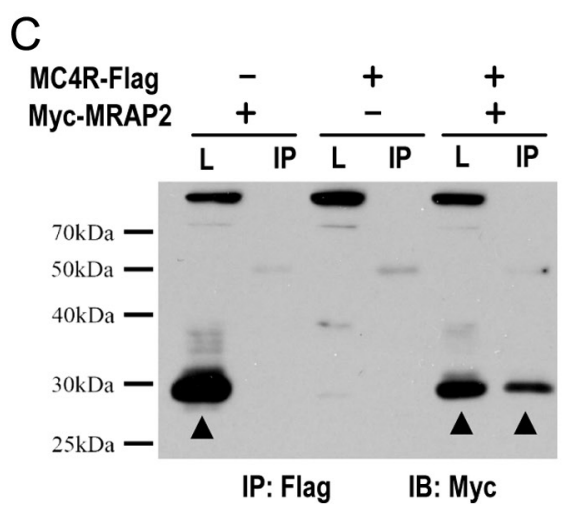

Figure 4

(A) Confocal microscopy showing the co-localization of Flag-cMC3R/Flag-cMC4R and Myc-cMRAP2 on the cell surface. Flag-cMC3R/Flag-cMC4R and Myc-CMRAP2 were transiently expressed in $\mathrm{CHO}$ cells and their expression was detected by Alexa-Fluor 488-conjugated anti-Flag antibody (green fluorescence) and Alexa-Fluor 594-conjugated anti-Myc antibody (red fluorescence) respectively. White arrows indicate the co-localization (yellow color) of MC3R/MC4R with MRAP2 on the cell surface. (B, C) Co-IP assay showing the interaction of Myc-CMRAP2 with cMC3R-Flag (B), or with CMC4R-Flag (C), in CHO cells co-transfected with cMRAP2 and CMC3R (or cMC4R) expression plasmids. Arrow heads in (B, C) indicate the positive MRAP2 band ( 27 kDa) in immuno-precipitated samples (IP) and cell lysates (L) detected by anti-Myc antibody. L, cell lysates; IP, immuno-precipitated samples (Anti-Flag antibody used); IB, immuno-blotting (anti-Myc antibody used).

when compared with $\mathrm{CHO}$ cells expressing cMC3R alone. Similarly, co-expression of cMRAP2 (or cMRAP) with cMC4R did not alter surface expression of cMC4R significantly, although a slight decrease in cMC4R surface expression was noted in the presence of cMRAP2. In sharp contrast, both cMRAP and cMRAP2 could enhance the surface expression of cMC2R significantly (Fig. 6), as previously reported in mammals (Chan et al. 2009, Sebag \& Hinkle 2009b).

\section{AgRP can act as an inverse agonist of $\mathrm{CMC} 3 \mathrm{R}$ and $\mathrm{CMC4R}$}

The strong constitutive activity of cMC3R led us to examine whether AgRP can act as an inverse agonist to inhibit the basal constitutive activity of cMC3R in vitro using pGL3-CRE-luciferase reporter system. As shown in
Fig. 5, human AgRP could effectively inhibit the basal luciferase activity of $\mathrm{CHO}$ cells expressing cMC3R with an $\mathrm{EC}_{50}$ value at $3.62 \pm 1.04 \mathrm{nM}$, indicating that AgRP can act as a potent inverse agonist of cMC3R. However, we noted that in the presence of cMRAP2, the inhibitory action of AgRP diminished considerably $\left(\mathrm{EC}_{50},>100 \mathrm{nM}\right)$. In contrast, in the presence of cMRAP, AgRP could still inhibit the basal activity of cMC3R effectively $\left(\mathrm{EC}_{50}\right.$ : $\sim 9.16 \pm 5.12 \mathrm{nM}$ ) (Table 1).

Unlike cMC3R, cMC4R basal activity could only be inhibited significantly by AgRP at a high concentration (100 nM) (Fig. 5), suggesting that AgRP may be a weak inverse agonist for cMC4R. Since the basal constitutive activity of cMC4R is relatively weak, it is rather difficult to judge whether cMRAP2 (or cMRAP) can modulate the inverse agonistic action of AgRP on cMC4R (Fig. 5). 
A
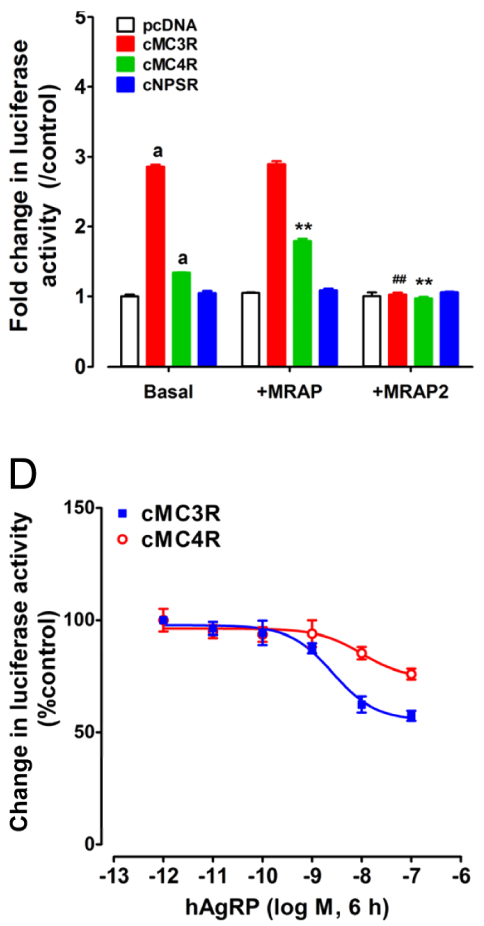

B
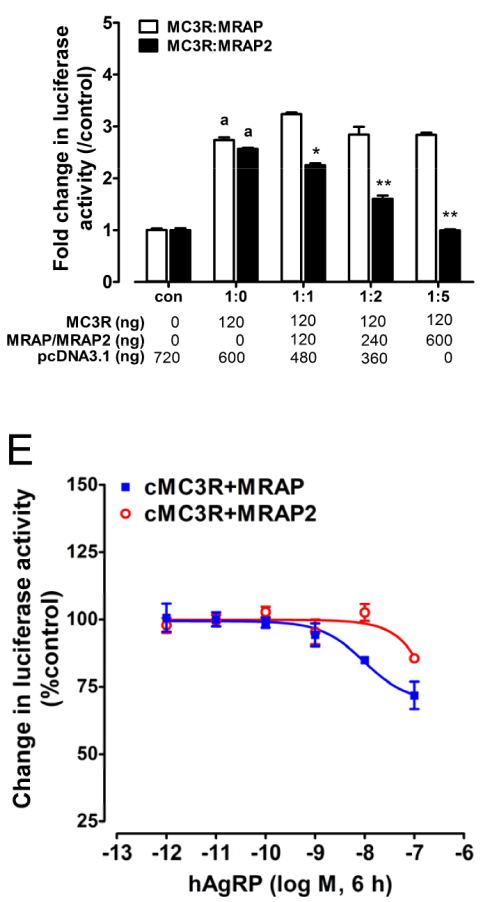

C
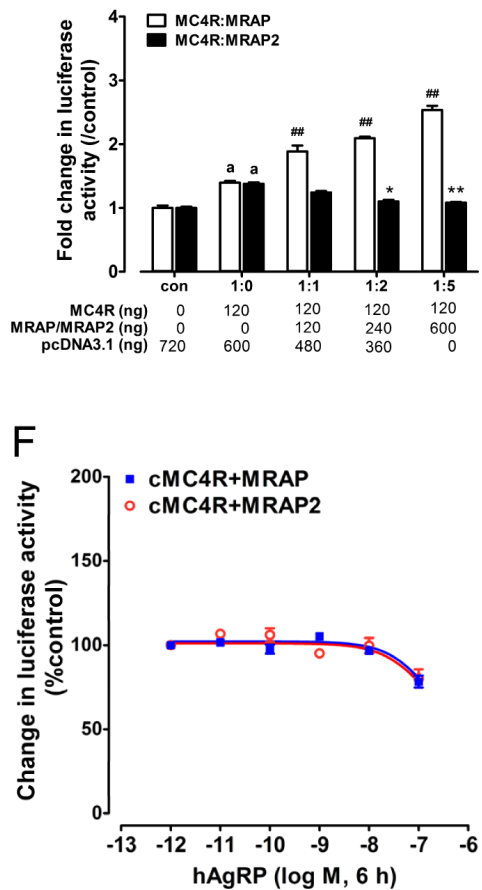

Figure 5

(A) The constitutive activity of CMC3R and CMC4R detected by dual-luciferase reporter assay. Both CMC3R and CMC4R demonstrate constitutive activity, and cMRAP2/cMRAP can modify (inhibit/enhance) their activity. In contrast, under the same conditions, chicken NPSR (cNPSR, a Gs protein-coupled receptor) shows no basal activity. CHO cells transfected with empty pcDNA3.1(+) vector was used as a control. aP $<0.001$ vs pcDNA3.1(+) control. $\# P<0.001$ vs CMC3R-expressing CHO cells; $* * P<0.001$ vs CMC4R-expressing $\mathrm{CHO}$ cells. The ratio of receptor to MRAP/MRAP2 plasmid used in these experiments is 1:5 (w/w). (B) The basal constitutive activity of CMC3R could be dose dependently inhibited by CMRAP2 (not cMRAP) plasmid, as indicated. (C) The basal constitutive activity of CMC4R could be dose dependently inhibited by CMRAP2 plasmid, as indicated, while its basal activity was enhanced by CMRAP dose dependently. In graphs (B) and (C), CHO cells transfected with empty pcDNA3.1(+) vector were used as a control (con). aP $<0.001$ vs control (con). ${ }^{*} P<0.05, * * P<0.001$ vs CMC3R/CMC4R-expressing CHO cells; $\# \# P<0.001$ vs CMC4R-expressing CHO cells. Each data point in (A, B and C)

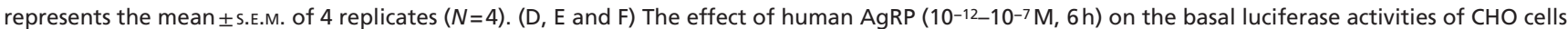
expressing CMC3R/CMC4R (D), or CHO cells co-transfected with CMC3R and CMRAP2/CMRAP plasmids (E), or CHO cells co-transfected with cMC4R and CMRAP2/CMRAP plasmids (F), as monitored by pGL3-CRE-luciferase reporter assay. Each data point in (D, E and F) represents the mean \pm S.E.M. of 3 replicates $(N=3)$. A full colour version of this figure is available at http://dx.doi.org/10.1530/JOE-17-0131.

\section{AgRP antagonizes ACTH/ $\alpha$-MSH actions on CMC3R and CMC4R}

To determine whether AgRP could antagonize $\alpha$-MSH/ ACTH action on cMC4R/cMC3R activation, $\mathrm{CHO}$ cells expressing cMC4R (or cMC3R) were co-treated by ACTH (or $\alpha$-MSH) (10nM) and human AgRP (0.1-100nM). As shown in Fig. 7, AgRP could block ACTH-induced luciferase activities of $\mathrm{CHO}$ cells expressing cMC3R or cMC4R dose dependently, as monitored by pGL3-CREluciferase reporter system. Similarly, AgRP could also effectively suppress ACTH-induced luciferase activities of $\mathrm{CHO}$ cells co-expressing cMC3R and cMRAP2 (or cMRAP) or $\mathrm{CHO}$ cells co-expressing cMC4R and cMRAP2 (or CMRAP).

In addition, AgRP could also suppress $\alpha$-MSH-induced luciferase activity of $\mathrm{CHO}$ cells expressing cMC4R/cMC3R, or $\mathrm{CHO}$ cells co-expressing cMC4R (or cMC3R) and cMRAP2 (or cMRAP) in a dose-dependent manner (Fig. 8).

\section{Tissue expression of MC3R, MC4R, AgRP, POMC, MRAP and MRAP2 in chickens}

Using quantitative real-time PCR, we further examined the mRNA expression of $c M C 4 R, c M C 3 R, c A g R P, c P O M C$, CMRAP and $C M R A P 2$ in adult chicken tissues, including various brain regions.

As shown in Fig. 9, $C M C 4 R$ is expressed predominantly in the hypothalamus and weakly in other tissues, including the midbrain, hindbrain, adrenal gland, anterior pituitary, fat, heart and small intestine. Like $c M C 4 R, c M C 3 R$ is expressed predominantly in the hypothalamus, and weakly in remaining tissues, 
A

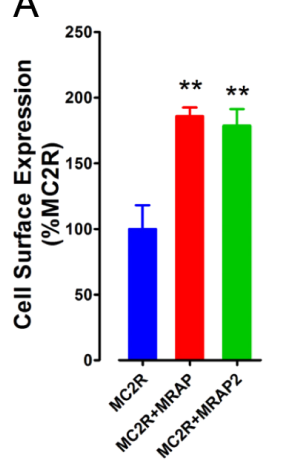

B
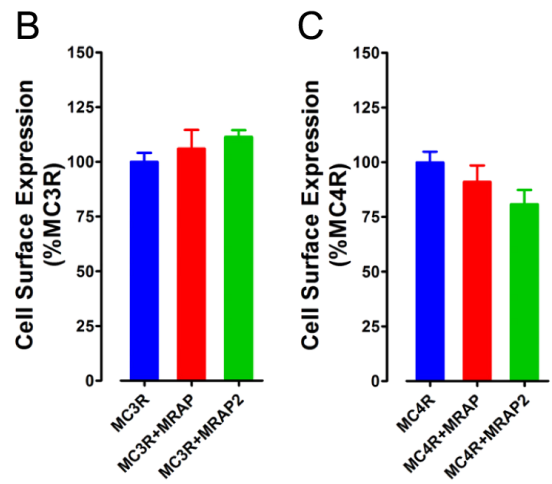

Figure 6

Surface expression of Flag-cMC2R (A), Flag-cMC3R (B) and Flag-cMC4R (C) in the absence or presence of CMRAP/CMRAP2. Surface expression levels of each receptor were detected by whole-cell ELISA assay and expressed as the percentage of $\mathrm{CHO}$ cells expressing Flag-cMC2R (or Flag-cMC3R/ Flag-cMC4R) alone. Each data point represents mean \pm s.E.M. of four replicates $(N=4) . * * P<0.001$ vs $\mathrm{CHO}$ cells expressing $\mathrm{CMC} 2 \mathrm{R}$ only. A full colour version of this figure is available at http://dx.doi.org/10.1530/ JOE-17-0131.

including anterior pituitary, ovary, muscle, adrenal gland and other brain regions.

Unlike the predominant expression of $c M C 3 R$ and $c M C 4 R$ in chicken hypothalamus, a differential expression of $C M R A P 2$ and $C M R A P$ was observed in chicken tissues. CMRAP2 mRNA is highly expressed in various brain regions (including the hypothalamus) and adrenal gland, while only a moderate or weak expression of $c M R A P 2$ was detected in other tissues, including the testes, pancreas and anterior pituitary. In contrast, $c M R A P$ is expressed predominantly in the adrenal gland and weakly in other tissues examined.

$c A g R P$ was detected to be expressed predominantly in the hypothalamus, moderately in the anterior pituitary, and weakly in the midbrain, cerebellum, hindbrain and spleen, while it was almost undetectable in other tissues examined. Unlike $c A g R P, C P O M C$ is highly expressed in the anterior pituitary, moderately in the hypothalamus, and weakly in other brain regions, lung, skin, fat and spleen. $C P O M C$ mRNA was barely detectable in other tissues examined.

\section{Regulation of hypothalamic CMRAP2 and CPOMC expression by fasting}

The abundant expression of $C M R A P 2$ and $C P O M C$ in chicken hypothalamus led us to further examine whether fasting could alter their expression in chick hypothalamus by quantitative real-time PCR. Since fasting is reported to upregulate the mRNA expression of $N P Y$ and $A g R P$, both of which are mainly co-expressed in the same neurons of avian hypothalamic infundibular nucleus (Boswell et al. 2002, Phillips-Singh et al. 2003), therefore, their expression was also examined in parallel and used as positive controls. As shown in Supplementary Fig. 2, 24-h and 36-h fasting caused a 6- to 8-fold increase in $c A g R P$ expression and a 2 - to 3-fold increase in $c N P Y$ expression. Interestingly, cMRAP2 mRNA levels also showed a slight, but significant, increase after 24 -h or 36 -h fasting. In contrast, POMC expression showed no significant variation after 24 -h fasting, but 36-h fasting caused a slight, but significant downregulation on its expression.

\section{Discussion}

MC4R(/MC3R) signaling has long been implicated to control energy balance in birds (Boswell \& Dunn 2015); however, the complex interaction of avian MC4R/ MC3R with MRAP2, AgRP and POMC-derived peptides remains unclear. Here, we elucidated that chicken MC4R and MC3R, when co-expressed with MRAP2 (or MRAP), show increased sensitivity and selectivity toward ACTH, and MRAP2 (and MRAP) can modulate their constitutive activity. Moreover, we demonstrated that AgRP can act as an inverse agonist for MC3R and MC4R, and it also antagonizes $\alpha-\mathrm{MSH} / \mathrm{ACTH}$ action on MC4R/MC3R. These findings, together with the co-expression of MRAP2, $P O M C, A g R P$ and $M C 4 R / M C 3 R$ in chicken hypothalamus, strongly suggest that these molecules may interact at the hypothalamic level to control avian energy balance. To our knowledge, this study represents the first to reveal an intricate interaction of MC3R/MC4R with MRAP2, $\alpha-\mathrm{MSH} / \mathrm{ACTH}$ and AgRP in an avian species and provide novel proof that MRAP2 (and MRAP) can modulate the constitutive activity and ligand sensitivity and selectivity of both MC3R and MC4R in vertebrates.

\section{Differential tissue expression of MRAP2 and MRAP in chickens}

In this study, MRAP2 cDNA was cloned from chicken brain. It encodes a single-pass membrane protein, which shows a remarkable conservation (45-74\% identity) with human MRAP2 or zebrafish MRAP2a/ MRAP2b, and a relatively low sequence identity (24-30\%) with chicken, Xenopus and human MRAP (Fig. 2). qPCR revealed that $C M R A P 2$ is highly expressed in the brain and adrenal gland. In contrast, $C M R A P$ is predominantly expressed in the adrenal gland 
A
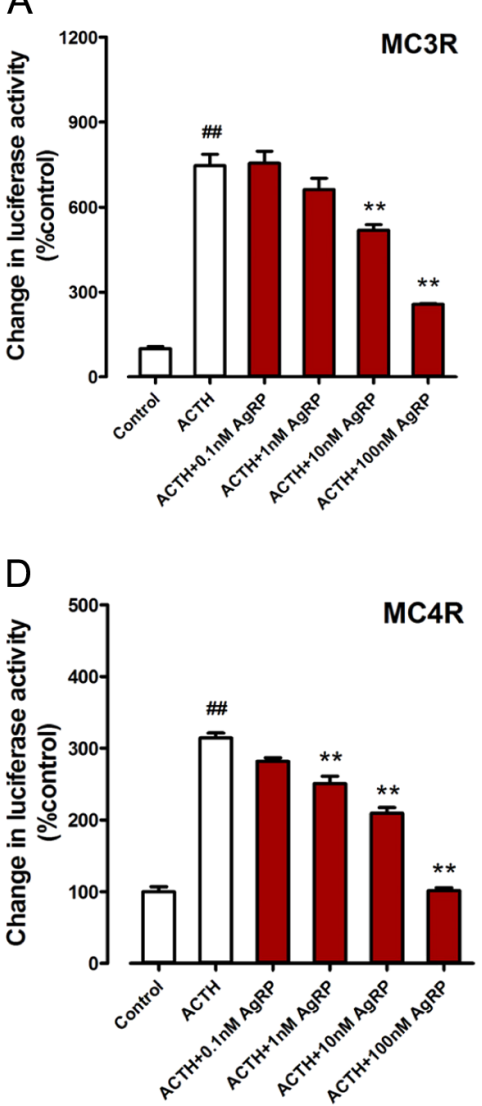

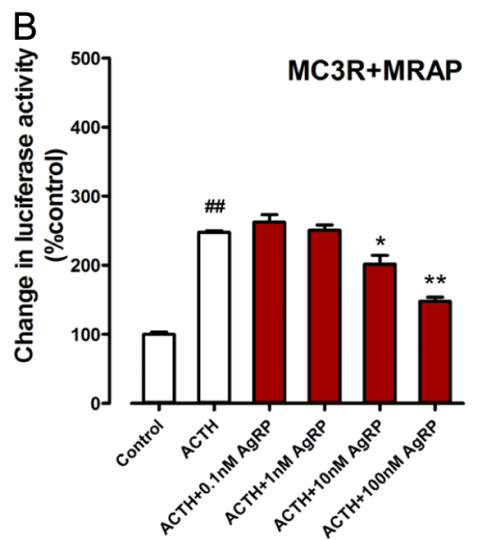

C

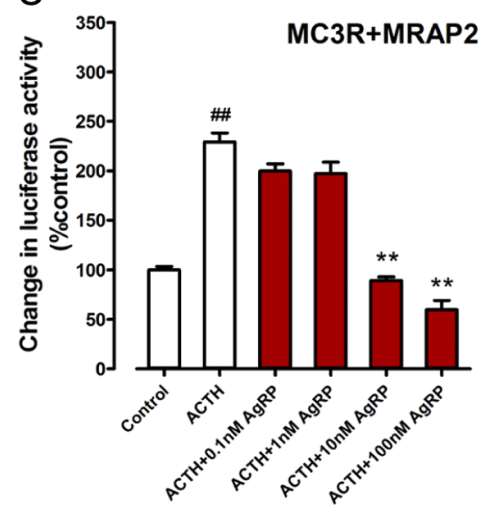

E

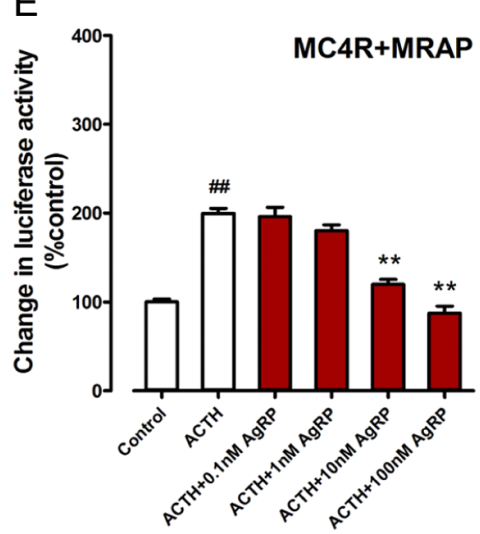

$\mathrm{F}$

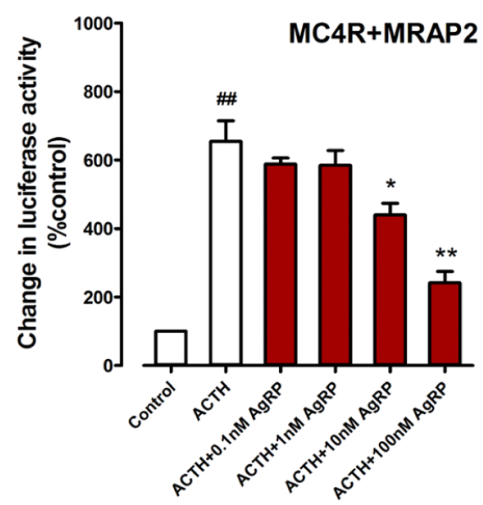

Figure 7

( $A, B$ and C) Human AgRP (0.1-100 nM, 6h) could dose dependently block ACTH $_{1-39}(10 \mathrm{nM})$-stimulated luciferase activity of CHO cells expressing cMC3R (A), or CHO cells co-expressing CMC3R and cMRAP (B), or CHO cells co-expressing CMC3R and cMRAP2 (C), as monitored by a pGL3-CRE-luciferase reporter system. ( $D$ and $E$ ) Human AgRP (0.1-100 nM, $6 \mathrm{~h}$ ) could dose dependently inhibit $\mathrm{ACTH}_{1-39}(10 \mathrm{nM})$-stimulated luciferase activity of CHO cells expressing CMC4R (D), or CHO cells co-expressing CMC4R and cMRAP (E), or CHO cells co-expressing CMC4R and CMRAP2 (F), as monitored by a pGL3-CRE-luciferase reporter system. Each data point represents the mean \pm s. E.M. of 3 replicates $(N=3)$. ${ }^{*} P<0.05 ;{ }^{*} P<0.001$ vs ACTH $1-39$ treatment; $\# P<0.001$ vs control (without peptide treatment). A full colour version of this figure is available at http://dx.doi.org/10.1530/JOE-17-0131.

(Fig. 9). Our finding coincides with the observations in mammals, in which MRAP is highly expressed in the adrenal cortex, and MRAP2 is mainly expressed in the brain and adrenal gland (Metherell et al. 2005, Sebag \& Hinkle 2007, Chan et al. 2009, Asai et al. 2013). The conserved expression patterns of MRAP and MRAP2 between birds and mammals suggest that as in mammals (Metherell et al. 2005, Sebag \& Hinkle 2007, Chan et al. 2009, Asai et al. 2013), MRAP is crucial for MC2R trafficking, ACTH binding (Fig. 3) and normal functions of the adrenal gland in chickens (Barlock et al. 2014), whereas MRAP2 may be crucial for MC4R/MC3R (and other non-melanocortin GPCR) functions in the brain (Chaly et al. 2016) and other non-brain tissues, such as the adrenal gland.

\section{MC4R and MC3R may act as potential ACTH-preferring receptors in the presence of MRAP2}

In this study, we found that chicken MC3R expressed in $\mathrm{CHO}$ cells can be potently activated by chicken $\alpha$-MSH, $\beta$-MSH, $\gamma$-MSH and $\mathrm{ACTH}_{1-39}$ with similarly high potencies. Our finding differs from a previous report, in which chicken MC3R expressed in HEK293 cells can bind to human $\gamma$-MSH $\left(K_{\mathrm{i}}=3.4 \mathrm{nM}\right)$ with a much higher affinity than to $\mathrm{ACTH}_{1-39}\left(K_{\mathrm{i}}=15.4 \mathrm{nM}\right), \alpha-\mathrm{MSH}\left(K_{\mathrm{i}}=24 \mathrm{nM}\right)$ and $\beta$-MSH $\left(K_{\mathrm{i}}=151 \mathrm{nM}\right)$ (Ling et al. 2004). This discrepancy may be due to the sequence difference between chicken and human melanocortins used in the two studies. Similar to our finding in chickens, MC3R can be activated by $\alpha$-MSH, $\beta$-MSH, $\gamma$-MSH and ACTH with similarly high 
A
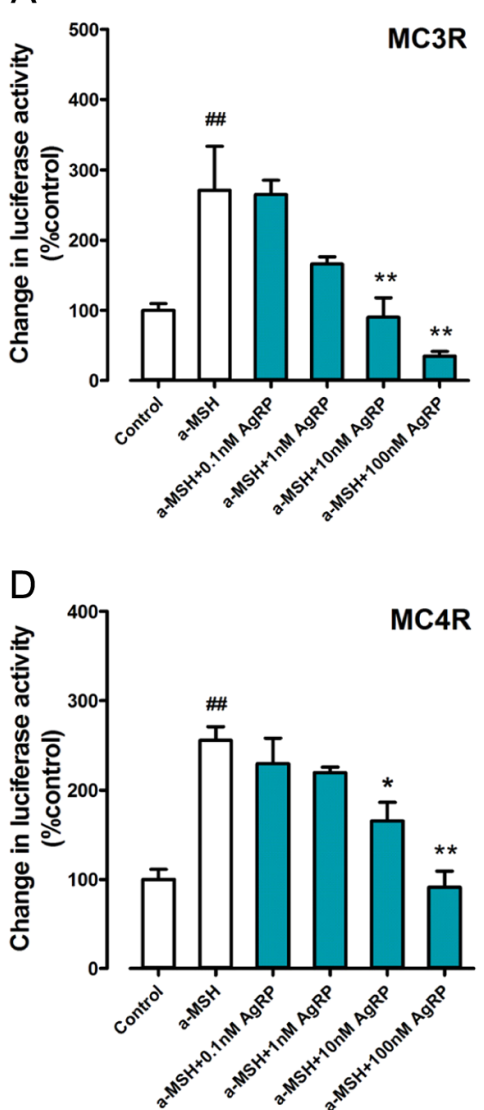

B

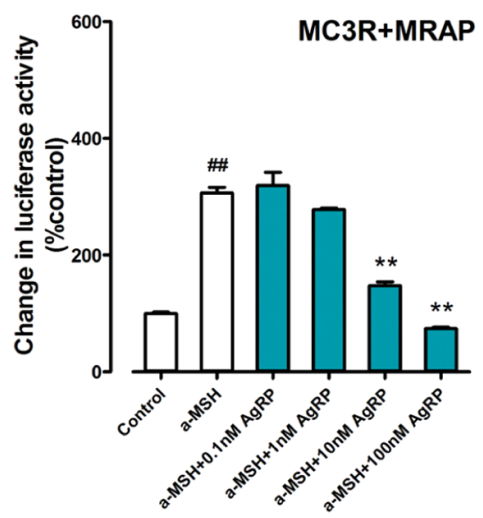

E

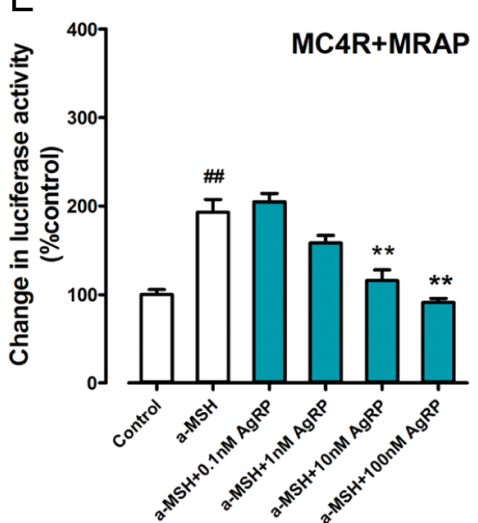

C

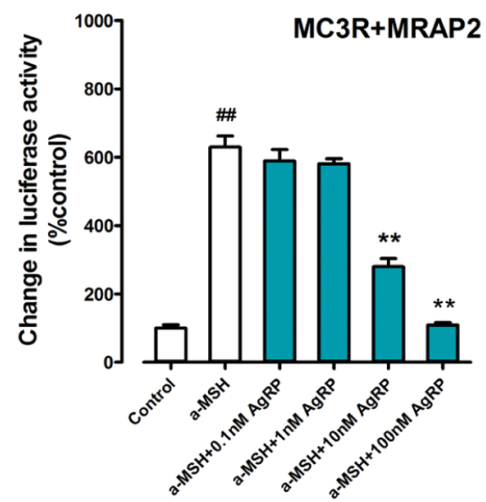

$\mathrm{F}$

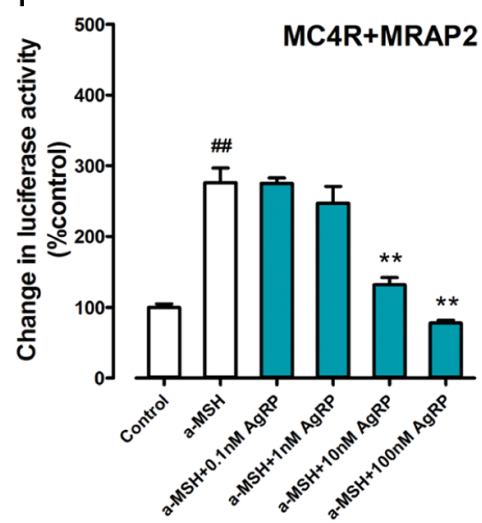

Figure 8

(A, B and C) Human AgRP (0.1-100 nM, 6h) could dose dependently inhibit $\alpha$-MSH (10 nM)-stimulated luciferase activity of CHO cells expressing cMC3R alone (A), or CHO cells co-expressing CMC3R and CMRAP (B), or CHO cells co-expressing CMC3R and cMRAP2 (C), as monitored by a pGL3-CRE-luciferase reporter system. (D, E and F) Human AgRP $(0.1-100 \mathrm{nM}, 6 \mathrm{~h})$ could dose dependently inhibit $\alpha$-MSH (10 nM)-stimulated luciferase activity of CHO cells expressing CMC4R alone (D), or CHO cells co-expressing CMC4R and CMRAP (E), or CHO cells co-expressing cMC4R and CMRAP2 (F), as monitored by a pGL3-CRE-luciferase reporter system. Each data point represents the mean \pm s.E.M. of 3 replicates $(N=3)$. ${ }^{*} P<0.05$; $* * P<0.001$ vs $\alpha$-MSH treatment; $\# P<0.001$ vs control (without peptide treatment). A full colour version of this figure is available at http://dx.doi.org/10.1530/JOE-17-0131.

potencies in mammals, indicating the conservation of pharmacological property between avian and mammalian MC3R (Gantz et al. 1993a, Roselli-Rehfuss et al. 1993, Cone 2006).

Unlike cMC3R, cMC4R displays a weak selectivity towards $\alpha$-MSH and $\mathrm{ACTH}_{1-39}$. Both $\alpha-\mathrm{MSH}$ and $\mathrm{ACTH}_{1-39}$ can activate cMC4R equipotently, with $\mathrm{EC}_{50}$ values in the nanomolar range, whereas $\beta$-MSH and $\gamma$-MSH are less potent $\left(\mathrm{EC}_{50},>10 \mathrm{nM}\right)$. Our data partly agree with the finding in humans, in which human MC4R expressed in COS- 1 or HEK293 cells can be activated by $\alpha-\mathrm{MSH}, \mathrm{ACTH}_{1-39}$ and $\beta$-MSH with similarly high potencies (Gantz et al. 1993b, Mountjoy et al. 1994).

There is growing evidence supporting that MRAP2 (and MRAP) can interact with all 5 MCRs, and by which they can modify MCR trafficking, ligand binding or signaling (Sebag \& Hinkle 2007, Chan et al. 2009, Asai et al. 2013,
Josep Agulleiro et al. 2013, Sebag et al. 2013, Dores 2016). In this study, we demonstrated that cMC3R and cMC4R, when co-expressed with cMRAP2 (or cMRAP), can be preferentially activated by $\mathrm{ACTH}$, and the potencies of ACTH increase 7- to 21-fold, as revealed by the significant shifts of $\mathrm{EC}_{50}$ values from nanomolar to sub-nanomolar ranges. By contrast, the potencies of $\alpha$-MSH in activating cMC3R/cMC4R only show a slight variation (Table 1 ). Moreover, we also found that cMRAP2 is more effective than cMRAP in enhancing the sensitivity of both receptors for ACTH in all experiments performed. These findings indicate that in the presence of MRAPs, particularly MRAP2, cMC3R and cMC4R can act as two potential ACTH-preferring receptors. The interaction between cMC3R/cMC4R and cMRAP2 in vitro was further confirmed by co-immunoprecipitation assay. Although the action of MRAP(s) in enhancing the sensitivity of MC3R/MC4R 
A

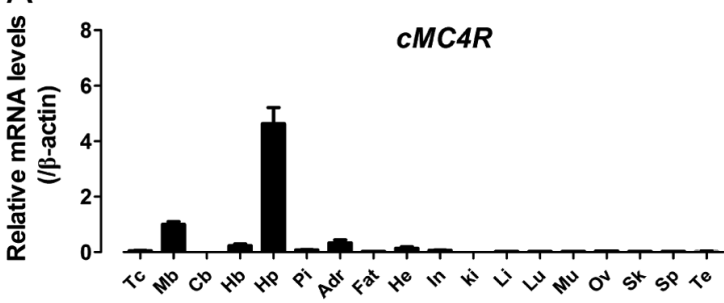

C

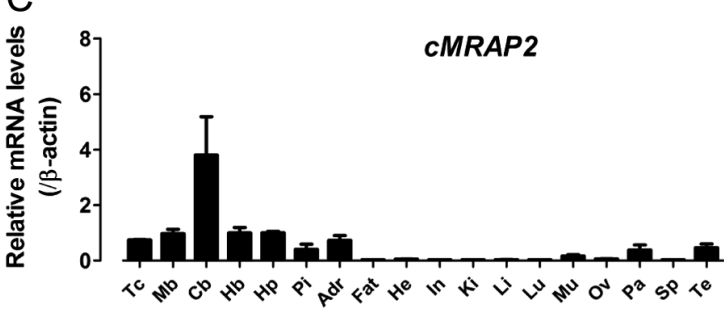

E

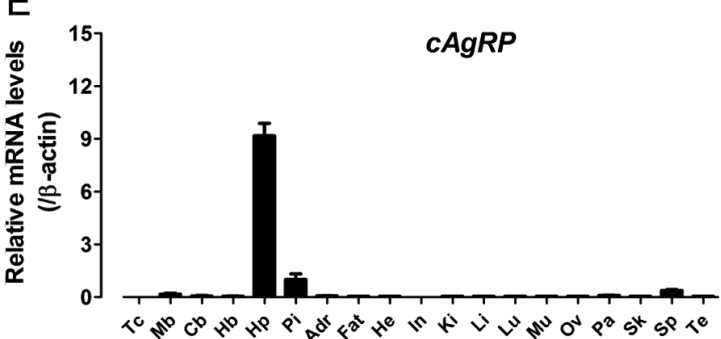

B

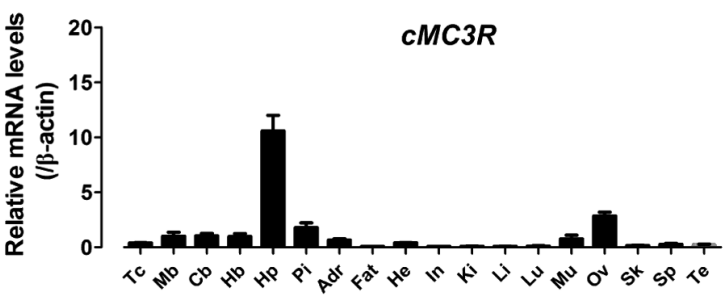

D

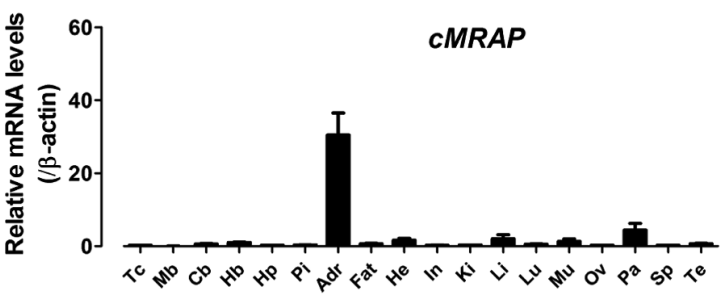

F

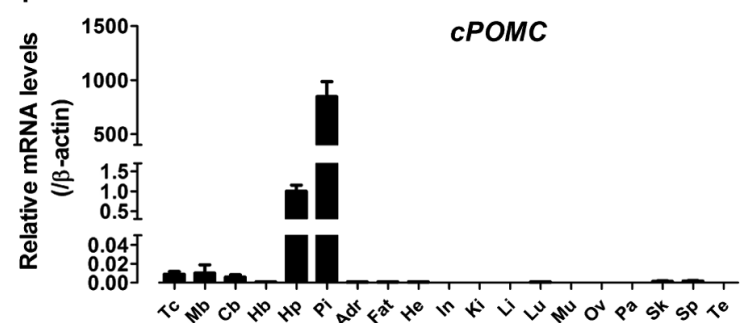

Figure 9

Quantitative real-time RT-PCR assay of $c M C 4 R(\mathrm{~A}), c M C 3 R(\mathrm{~B}), \mathrm{CMRAP2}(\mathrm{C}), \mathrm{CMRAP}(\mathrm{D}), \mathrm{CAgRP}(\mathrm{E})$ and $C P O M C(\mathrm{~F}) \mathrm{mRNA}$ expression in various chicken tissues, including the telencephalon ( $\mathrm{Tc})$, midbrain (Mb), cerebellum (Cb), hindbrain (Hb), hypothalamus (Hp), anterior pituitary (Pi), adrenal gland (Adr), subcutaneous fat (fat), heart (He), duodenum (in), kidneys (Ki), liver (Li), lung (Lu), muscle (Mu), ovary (Ov), pancreas (Pa), skin (Sk), spleen (Sp) and testes (Te). The mRNA levels of target genes were normalized to that of $\beta$-actin and expressed as the fold difference compared with that of the midbrain $(A, B)$, or hindbrain (C, D), or pituitary (E), or hypothalamus (F). Each data point represents the mean \pm S.E.M. of 6 adult chickens (3 males and 3 females) $(N=6)$

for ACTH has not been reported in any mammalian species, there is solid evidence showing the interaction of MRAP2/MRAP with MC4R/MC3R (Chan et al. 2009). For instance, MRAP2 can interact with MC4R and enhance its cAMP signaling in mice, and MRAP2 deletion or mutation causes severe obesity, possibly due to impaired MC4R signaling in mice and humans (Asai et al. 2013). In zebrafish, both MRAP2a and MRAP2b have been shown to interact with MC4R (Sebag et al. 2013). MRAP2a can reduce the binding of MC4R to $\alpha$-MSH, possibly by decreasing its binding sites, while MRAP2b can regulate MC4R activity by increasing $\alpha$-MSH sensitivity and suppressing receptor constitutive activity (Sebag et al. 2013). Interestingly, in partial accordance with our findings in chickens, Josep Agulleiro and coworkers reported that co-expression of zebrafish MC4R with MRAP2a, and not MRAP2b (or MRAP), can increase the sensitivity of MC4R for $\mathrm{ACTH}_{1-24}$, thus becoming an ACTH receptor
(Josep Agulleiro et al. 2013). Our findings, together with the previous report in zebrafish, suggest that in addition to modifying the signaling of MC4R and MC3R, MRAP(s), particularly MRAP2, can also increase the sensitivity of MC4R and MC3R towards ACTH in birds, and maybe in some other vertebrates as well (Josep Agulleiro et al. 2013).

The cMRAP2-associated enhancement on potencies of ACTH in CMC4R and CMC3R activation (Table 1), together with the co-expression of cMRAP2, cMC4R and cMC3R in chicken hypothalamus, led us to hypothesize that like $\alpha-\mathrm{MSH}, \mathrm{ACTH}$ may play active roles via interaction with cMC4R/cMC3R-cMRAP2 complex in the hypothalamus, such as controlling food intake and body weight in chickens (Fig. 10). Consistent with this speculation, central injection of ACTH can inhibit food intake in chicks (Shipp et al. 2015), as reported in rats and zebrafish (Poggioli et al. 1986, Vergoni et al. 1986, Al-Barazanji et al. 2001, Josep Agulleiro et al. 2013).

Published by Bioscientifica Ltd. 
A

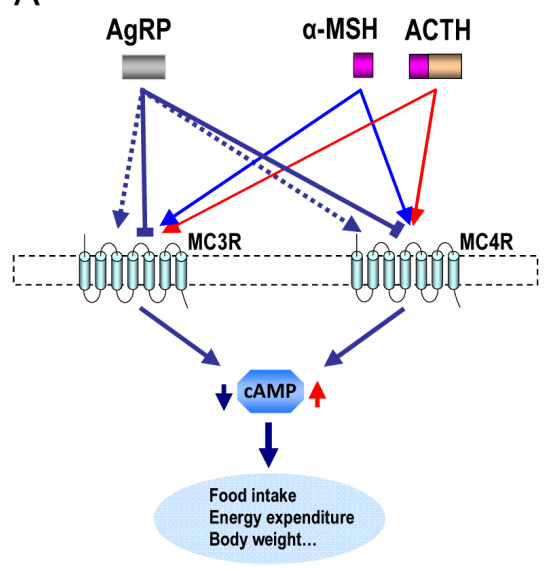

B

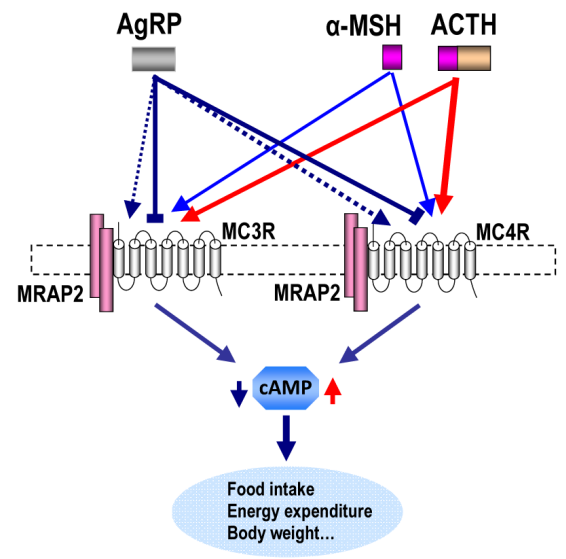

\section{Figure 10}

Proposed interaction of MC3R/MC4R with MRAP2, POMC-derived peptides ( $\alpha$-MSH/ACTH), and AgRP in chicken hypothalamus. (A) In the absence of MRAP2, both MC3R and MC3R are constitutively active receptors, and they can be further activated by $\alpha$-MSH and ACTH equipotently (arrows). AgRP can function either as an inverse agonist to inhibit the basal constitutive activity of MC3R/MC4R (dotted arrows), or as an antagonist to block $\alpha-\mathrm{MSH} /$ ACTH action on MC4R/MC3R (bold bars). (B) In the presence of MRAP2 (homodimer), MRAP2 can not only block the basal constitutive activity of MC3R/ MC4R, possibly by altering their conformation into an inactivated state (Sebag et al. 2013), but also enhance the sensitivity of both receptors for ACTH (bold arrows) (Table 1). Although the inverse agonistic action of AgRP on MC3R is likely attenuated by MRAP2, AgRP can still antagonize $\alpha$-MSH/ACTH action on MC4R/MC3R effectively. In brief summary, MRAP2 can interact with MC4R (and MC3R), and thus, fine-tune their constitutive activity, ligand sensitivity and selectivity, and downstream signaling intensity (e.g. cAMP and other signaling pathways). This interaction may work in chicken hypothalamus to regulate food intake, energy expenditure, metabolism and body weight gain (Qiu et al. 2006, Boswell \& Dunn 2015). Moreover, our data imply that like $\alpha-\mathrm{MSH}, \mathrm{ACTH}$ may play active roles in other physiological processes, such as energy balance, metabolism and body weight gain via interaction with MC4R/MC3R (A) or MC4R/MC3R-MRAP2 complex (B), in addition to being a key player in the pituitary-adrenal axis in chickens. Interestingly, MRAP can also enhance the sensitivity of MC4R/MC3R for ACTH; however, it seems less effective than MRAP2. Moreover, unlike MRAP2, MRAP cannot inhibit basal constitutive activity of MC4R/MC3R, it enhances the basal activity of MC4R instead. Therefore, the question whether the interaction of MC4R/MC3R with MRAP is physiologically relevant remains open to discussion. A full colour version of this figure is available at http://dx.doi.org/10.1530/JOE-17-0131.

Moreover, there are substantial evidence showing that repeated peripheral injections of ACTH into immature chickens usually decrease their growth rate and body weight gain, accompanied by unaltered (or increased) plasma growth hormone levels, adrenal hypertrophy and reduction in size of their lymphoid organs (Freeman \& Manning 1975, Davison et al. 1979). Since POMC is abundantly expressed in both hypothalamus and anterior pituitary (Fig. 9), it is tempting to speculate that ACTH derived from avian hypothalamus or pituitary may be capable of interacting with cMC4R(/cMC3R)-cMRAP2 complex expressed in the hypothalamus to control energy balance (Fig. 10). Moreover, it should be noted that unlike other vertebrates, birds lack an intermediate lobe of pituitary (Scanes 2015), where $\alpha$-MSH is mainly produced in most vertebrates. This unique anatomical feature of the avian pituitary also highlights the importance of pituitary ACTH actions on avian tissues, including its actions on the CNS (e.g. hypothalamus) and peripheral tissues. Presumably, chicken pituitary ACTH may be transported to the brain, as demonstrated in mammals (Bergland \& Page 1979, Bergland et al. 1980), and thus, regulate certain CNS-associated physiological processes, such as food intake in chickens (Shipp et al. 2015). Future studies on these aspects may help to reveal the novel facets of ACTH, derived both centrally (e.g. hypothalamus) and peripherally (e.g. anterior pituitary), in the control of energy balance, metabolism and body weight, in addition to its classic action on the pituitary-adrenal axis (Davison et al. 1979, Scanes 2015). Meanwhile, our findings also highlight the need to rethink the role of ACTH in energy balance of mammals and teleosts, as the existence and/or anorexic action of ACTH in the hypothalamus have been reported in both groups of vertebrates (Krieger et al. 1977, O'Donohue \& Dorsa 1982, Vergoni et al. 1986, Josep Agulleiro et al. 2013).

\section{CMRAP2(/cMRAP) can modulate the constitutive activity of CMC3R and CMC4R}

In this study, we revealed that both cMC3R and cMC4R display constitutive activity, as their mammalian orthologs (Ollmann et al. 1997, Nijenhuis et al. 2001, Wang et al. 2016). This finding suggests that cMC4R or cMC3R alone may regulate the physiological processes in the CNS and

Published by Bioscientifica Ltd. 
peripheral tissues, such as the tonic inhibition of feeding behavior in the hypothalamus, without the involvement of their endogenous agonists, or antagonist.

Interestingly, we noted that cMRAP2, but not cMRAP, can completely inhibit the strong constitutive activity of cMC3R. To our knowledge, this finding has not been reported in any vertebrate species before. However, analogous to our finding in chickens, the constitutive activity of MC4R can be inhibited by MRAP2 (MRAP2b) in mice and zebrafish (Asai et al. 2013, Josep Agulleiro et al. 2013, Sebag et al. 2013). Since cMC3R could still be activated by ACTH preferentially and potently in the presence of cMRAP2 (Fig. 3), we speculated that cMRAP2 may play an active role in stabilizing or locking cMC3R in an inactive conformation and conferring the sensitivity of cMC3R to ACTH (Fig. 10), rather than reducing its cell surface expression (Fig. 6).

Although cMC4R has a weak constitutive activity, cMRAP2 still shows considerable inhibition on its activity. Our finding is in accordance with the findings in mice and zebrafish, in which MRAP2 (or MRAP2b) can block the constitutive activity of MC4R (Asai et al. 2013, Sebag et al. 2013). Interestingly, we also observed that cMRAP can enhance the basal luciferase activity of $\mathrm{CHO}$ cells expressing cMC4R. Similar to our finding, Kay and coworkers also reported that MRAP can increase the constitutive activity of human MC4R transiently expressed in HEK293 cells (Kay et al. 2013). These findings indicate the distinct roles of MRAP and MRAP2 in modulating the constitutive activity of MC4R in birds and mammals (Fig. 5).

\section{AgRP functions as inverse agonist and antagonist of CMC3R and CMC4R}

In this study, we found that AgRP can potently inhibit the constitutive activity of cMC3R, indicating that AgRP can act as a potent inverse agonist for MC3R. Interestingly, we also noted that in the presence of cMRAP2, AgRP is much less potent in its inhibition on MC3R basal activity. This may be due to the masking of the inhibitory effect of AgRP by cMRAP2, rather than the reduction in the affinity of cMC3R for AgRP, since AgRP could still antagonize $\alpha-\mathrm{MSH} / \mathrm{ACTH}$ action effectively on CHO cells co-expressing cMC3R and cMRAP2 (Figs 7 and 8).

Unlike that of cMC3R, the weak basal activity of cMC4R could only be inhibited by AgRP at a high concentration $(100 \mathrm{nM})$. Our finding differs slightly from that in mammals, in which AgRP can inhibit the strong constitutive activity of MC4R effectively (Ollmann et al. 1997, Haskell-Luevano \& Monck 2001, Nijenhuis et al. 2001, Ghamari-Langroudi et al. 2015). The weak basal activity of cMC4R also prevented us from drawing a conclusion on whether cMRAP2/cMRAP could modulate the inverse agonistic action of AgRP on cMC4R. In spite of this uncertainty, our data suggest that AgRP alone can inhibit the constitutive activity of MC4R/MC3R and thus regulate some physiological processes, such as induction of food intake in birds and mammals (Rossi et al. 1998, Tachibana et al. 2001, Strader et al. 2003), in an $\alpha-\mathrm{MSH} /$ ACTH-independent manner.

It was hypothesized that AgRP can block the anorexic action of $\alpha-\mathrm{MSH}$, possibly through interaction with MC4R(/MC3R) in avian hypothalamus (Tachibana et al. 2001, Strader et al. 2003, Boswell \& Dunn 2015, Dunn et al. 2015); however, this hypothesis has been without experimental validation until now. Here, we demonstrated that AgRP can effectively antagonize $\alpha-\mathrm{MSH} / \mathrm{ACTH}$ actions on $\mathrm{cMC} 4 \mathrm{R}(/ \mathrm{cMC} 3 \mathrm{R})$ in vitro (Figs 7 and 8), indicating that as in mammals and teleosts (Ollmann et al. 1997, Song \& Cone 2007), AgRP can function as a potent antagonist for MC4R and MC3R in birds as well. Furthermore, we proved that in the presence of cMRAP2 (or cMRAP), AgRP can still antagonize $\alpha-\mathrm{MSH} / \mathrm{ACTH}$ actions on cMC4R/cMC3R effectively. Similar to our findings in chickens, AgRP can antagonize $\mathrm{ACTH}_{1-24}$ action on MC4R in the presence of MRAP2a in zebrafish (Song \& Cone 2007). These findings suggest that in vivo, AgRP can act as an antagonist to block $\alpha-\mathrm{MSH} / \mathrm{ACTH}$ actions on MC4R/MC3R effectively, regardless of the presence or absence of MRAP2 (or MRAP).

\section{Co-expression of MRAP2, AgRP, POMC, MC3R and MC4R in chicken hypothalamus}

The intricate interaction of MRAP2, MRAP, ACTH/ $\alpha-\mathrm{MSH}$ and AgRP with MC4R/MC3R in vitro led us to further examine their spatial expression in chickens. We found that both $M C 3 R$ and $M C 4 R$ are predominantly expressed in chicken hypothalamus. The predominant expression of $c M C 4 R / C M C 3 R$, together with the abundant expression of $C M R A P 2$ in chicken hypothalamus (Fig. 9), strongly suggests that as in mammals and zebrafish (Asai et al. 2013, Josep Agulleiro et al. 2013, Sebag et al. 2013), cMRAP2 may be co-expressed with cMC4R(/cMC3R) in some neurons, and thus, can fine-tune the constitutive activity, ligand sensitivity and selectivity, and signaling of $\mathrm{cMC} 4 \mathrm{R}(/ \mathrm{cMC} 3 \mathrm{R})$ and orchestrate the actions of $\alpha-\mathrm{MSH} /$ ACTH and AgRP on energy balance (Fig. 10). As cMRAP http://joe.endocrinology-journals.org DOI: $10.1530 / J O E-17-0131$ (c) 2017 Society for Endocrinology Printed in Great Britain
Published by Bioscientifica Ltd 
expression is extremely low in chicken hypothalamus, it is unlikely that it is involved in this action therein.

Apart from $c M C 3 R, c M C 4 R$ and $c M R A P 2, c A g R P$ is also predominantly expressed in chicken hypothalamus (Fig. 9), where abundant expression of $\triangle P O M C$ was found therein. Our findings further support the notion that $\mathrm{AgRP}(/ \mathrm{NPY})$ neurons and POMC neurons residing in the infundibular nucleus (Boswell et al. 2002, Phillips-Singh et al. 2003) may act as two key signaling centers to control energy balance through interaction with MC4R(/MC3R) (Boswell \& Dunn 2015), or MC4R(/MC3R)-MRAP2 complex, in chicken hypothalamus (Fig. 10).

\section{Regulation of MRAP2, POMC, AgRP and NPY expression by fasting: implications for their involvement in energy balance}

Since POMC and MRAP2 are abundantly expressed in chicken hypothalamus (Fig. 9), thus, we further examined whether MRAP2 and POMC expression in chicken hypothalamus, like $A g R P$ and $N P Y$, could also be regulated by fasting (Boswell et al. 2002). We found that both 24-h and 36-h fasting can induce $c A g R P$ and $c N P Y$ mRNA expression (Supplementary Fig. 2), as previously reported (Boswell et al. 2002, Phillips-Singh et al. 2003, Dunn et al. 2013, 2015). In contrast, 24-h fasting cannot alter $c P O M C$ mRNA level, while 36-h fasting downregulates expression (Supplementary Fig. 2). These findings, together with evidence showing the expression of the functional receptors for NPY (Yi et al. 2015, He et al. 2016, Gao et al. 2017) and $\alpha$-MSH/ACTH (cMC4R/cMC3R) in chicken hypothalamus, supports the notion that the elevated cAgRP (and CNPY) production may stimulate food intake by activating neuronal feeding pathways via NPY receptor(s) and blocking cMC4R(/cMC3R)regulated anorexic pathways under negative energy status (Kuenzel et al. 1987, Tachibana et al. 2001, Boswell et al. 2002, Phillips-Singh et al. 2003, Boswell \& Dunn 2015). Meanwhile, the downregulated $C P O M C$ expression may further reduce the anorexic action of $\alpha-\mathrm{MSH} / \mathrm{ACTH}$ simultaneously. Interestingly, we also noted that fasting can increase $C M R A P 2$ expression, as reported in zebrafish (MRAP2b) (Josep Agulleiro et al. 2013), implying that the increased $C M R A P 2$ expression may inhibit the basal constitutive activity of cMC4R/cMC3R, thus also driving food intake under negative energy status.

It is well documented that in mammals, hypothalamic $A g R P$ and POMC expression is regulated by peripheral metabolic signals, such as leptin (LEP) derived from adipose tissue (Morton et al. 2006). However, recently, we and others both revealed that little or no LEP expression could be detected in adipose tissue of zebra finches, chickens and ducks (Huang et al. 2014, Seroussi et al. 2016). These findings hint that birds harbor a regulatory network of energy balance different from the model established in mammals (Huang et al. 2014, Boswell \& Dunn 2015, Seroussi et al. 2016), in which avian leptin may not act as an adipocyte-derived signal to control energy balance (Huang et al. 2014, Seroussi et al. 2016). However, the co-expression of $M C 4 R(/ M C 3 R), A g R P$, $P O M C$ and MRAP2 in the hypothalamus, together with the interaction of MC4R/MC3R with AgRP, $\alpha$-MSH/ACTH and MRAP2, noted in zebrafish, chickens (Figs 9 and 10) and mammals (Asai et al. 2013, Josep Agulleiro et al. 2013, Sebag et al. 2013), still highlight the conserved roles of this interaction network (Fig. 10) in energy balance, metabolism and growth across vertebrates (Cone 2006, Cerda-Reverter et al. 2011, Boswell \& Dunn 2015). Undoubtedly, our study sets a cornerstone towards uncovering the conserved roles of MC4R/MC3R signaling in energy homeostasis of birds, a group of endothermic vertebrates adopting diverse and fascinating energy balance strategies (Huang et al. 2014).

In summary, we revealed an intricate interaction network of MC4R/MC3R with $\alpha$-MSH/ACTH, AgRP and MRAP2 (/MRAP) in chickens. As in mammals/teleosts, $\alpha$ MSH/ACTH can activate MC4R and MC3R in chickens, while AgRP can antagonize $\alpha-\mathrm{MSH} / \mathrm{ACTH}$ actions on MC4R/MC3R and lower the constitutive activity of both receptors. Interestingly, we also found that MRAP2 can enhance the sensitivity of MC4R (and MC3R) for ACTH and block the constitutive activity of both receptors. These findings, together with evidence showing the co-expression of POMC, AgRP, MC4R, MC3R and MRAP2 in chicken hypothalamus and the opposite central actions of AgRP and $\alpha-\mathrm{MSH}(/ \mathrm{ACTH})$ on food intake, suggest that within the hypothalamus, AgRP and $\alpha-\mathrm{MSH}(/ \mathrm{ACTH})$ may act in a coordinated manner on the MC4R(/MC3R)-MRAP2 complex, or MC4R/MC3R, to control energy balance in birds (Fig. 10), in a way similar to that in mammals/teleosts. Meanwhile, the increased sensitivity of $\mathrm{cMC} 4 \mathrm{R}(/ \mathrm{cMC} 3 \mathrm{R})$ for ACTH in the presence of MRAP2(/MRAP) also implies that like $\alpha-\mathrm{MSH}, \mathrm{ACTH}$, via interaction with $\mathrm{MC} 4 \mathrm{R} / \mathrm{MC} 3 \mathrm{R}$, may be involved in the regulation of energy balance and other physiological processes, representing a potential new facet of ACTH actions, which may have long been 'masked' 
by the actions of $\alpha-\mathrm{MSH}$ and warrant our attention in future studies.

\section{Notes}

During the course of our manuscript preparation, Dores and coworkers also described that chicken MRAP and MRAP2 can enhance the sensitivity of chicken MC3R and MC4R expressed in CHO cells for human $\mathrm{ACTH}_{1-24}$ in an abstract (Dores et al. 2016b), which partially coincides with some findings presented in our study. Chicken MRAP2 cDNA sequence was submitted to GenBank in 2015 under an accession no.: KT183012.

\section{Supplementary data}

This is linked to the online version of the paper at $h t t p: / / d x . d o i . o r g / 10.1530 /$ JOE-17-0131.

\section{Declaration of interest}

The authors declare that there is no conflict of interest that could be perceived as prejudicing the impartiality of the research reported.

\section{Funding}

This work was supported by grants from the National Natural Science Foundation of China (31572391, 31472089, 31271325).

\section{References}

Agulleiro MJ, Roy S, Sanchez E, Puchol S, Gallo-Payet N \& CerdaReverter JM 2010 Role of melanocortin receptor accessory proteins in the function of zebrafish melanocortin receptor type 2. Molecular and Cellular Endocrinology 320 145-152. (doi:10.1016/j.mce.2010.01.032)

Al-Barazanji KA, Miller JE, Rice SQ, Arch JR \& Chambers JK 2001 C-terminal fragments of ACTH stimulate feeding in fasted rats. Hormone and Metabolic Research 33 480-485. (doi:10.1055/s-2001-16941)

Asai M, Ramachandrappa S, Joachim M, Shen Y, Zhang R, Nuthalapati N, Ramanathan V, Strochlic DE, Ferket P, Linhart K, et al. 2013 Loss of function of the melanocortin 2 receptor accessory protein 2 is associated with mammalian obesity. Science $\mathbf{3 4 1} 275-278$. (doi:10.1126/science.1233000)

Barlock TK, Gehr DT \& Dores RM 2014 Analysis of the pharmacological properties of chicken melanocortin- 2 receptor (cMC2R) and chicken melanocortin-2 accessory protein 1 (cMRAP1). General and Comparative Endocrinology 205 260-267. (doi:10.1016/j. ygcen.2014.03.045)

Bergland RM \& Page RB 1979 Pituitary-brain vascular relations: a new paradigm. Science 204 18-24. (doi:10.1126/science.373118)

Bergland R, Blume H, Hamilton A, Monica P \& Paterson R 1980 Adrenocorticotropic hormone may be transported directly from the pituitary to the brain. Science 210 541-543. (doi:10.1126/ science.6252607)
Boswell T \& Dunn IC 2015 Regulation of the avian central melanocortin system and the role of leptin. General and Comparative Endocrinology 221 278-283. (doi:10.1016/j.ygcen.2014.12.009)

Boswell T, Li Q \& Takeuchi S 2002 Neurons expressing neuropeptide $\mathrm{Y}$ mRNA in the infundibular hypothalamus of Japanese quail are activated by fasting and co-express agouti-related protein mRNA. Brain Research: Molecular Brain Research 100 31-42. (doi:10.1016/ S0169-328X(02)00145-6)

Butler AA, Kesterson RA, Khong K, Cullen MJ, Pelleymounter MA, Dekoning J, Baetscher M \& Cone RD 2000 A unique metabolic syndrome causes obesity in the melanocortin-3 receptor-deficient mouse. Endocrinology 141 3518-3521. (doi:10.1210/endo.141.9.7791)

Cai G, Mo C, Huang L, Li J \& Wang Y 2015 Characterization of the two CART genes (CART1 and CART2) in chickens (Gallus gallus). PLoS ONE 10 e0127107. (doi:10.1371/journal.pone.0127107)

Cawley NX, Li Z \& Loh YP 201660 YEARS OF POMC: biosynthesis, trafficking, and secretion of pro-opiomelanocortin-derived peptides. Journal of Molecular Endocrinology 56 T77-T97. (doi:10.1530/JME-150323)

Cerda-Reverter JM, Schioth HB \& Peter RE 2003 The central melanocortin system regulates food intake in goldfish. Regulatory Peptides 115 101-113. (doi:10.1016/S0167-0115(03)00144-7)

Cerda-Reverter JM, Agulleiro MJ, R RG, Sanchez E, Ceinos R \& Rotllant J 2011 Fish melanocortin system. European Journal of Pharmacology 660 53-60. (doi:10.1016/j.ejphar.2010.10.108)

Chaly AL, Srisai D, Gardner EE \& Sebag JA 2016 The melanocortin receptor accessory protein 2 promotes food intake through inhibition of the prokineticin receptor-1. eLife $\mathbf{5}$ e12397.

Chan LF, Webb TR, Chung TT, Meimaridou E, Cooray SN, Guasti L, Chapple JP, Egertova M, Elphick MR, Cheetham ME, et al. 2009 MRAP and MRAP2 are bidirectional regulators of the melanocortin receptor family. PNAS 106 6146-6151. (doi:10.1073/pnas.0809918106)

Chen P, Li C, Haskell-Luevano C, Cone RD \& Smith MS 1999 Altered expression of agouti-related protein and its colocalization with neuropeptide $\mathrm{Y}$ in the arcuate nucleus of the hypothalamus during lactation. Endocrinology 140 2645-2650. (doi:10.1210/ endo.140.6.6829)

Chen AS, Marsh DJ, Trumbauer ME, Frazier EG, Guan XM, Yu H, Rosenblum CI, Vongs A, Feng Y, Cao L, et al. 2000 Inactivation of the mouse melanocortin-3 receptor results in increased fat mass and reduced lean body mass. Nature Genetics 26 97-102. (doi:10.1038/79254)

Chhajlani V \& Wikberg JE 1992 Molecular cloning and expression of the human melanocyte stimulating hormone receptor cDNA. FEBS Letters 309 417-420. (doi:10.1016/0014-5793(92)80820-7)

Cline MA, Nandar W, Bowden C, Hein PP, Denbow DM \& Siegel PB 2008 Differential feeding responses to central alpha-melanocyte stimulating hormone in genetically low and high body weight selected lines of chickens. Life Science 83 208-213. (doi:10.1016/j. lfs.2008.06.003)

Cone RD 2006 Studies on the physiological functions of the melanocortin system. Endocrine Reviews 27 736-749. (doi:10.1210/ er.2006-0034)

Davison TF, Scanes CG, Flack IH \& Harvey S 1979 Effect of daily injections of ACTH on growth and on the adrenal and lymphoid tissues of two strains of immature fowls. British Poultry Science $\mathbf{2 0}$ 575-585. (doi:10.1080/00071667908416624)

Dores RM 2016 Hypothesis and theory: revisiting views on the co-evolution of the melanocortin receptors and the accessory proteins, MRAP1 and MRAP2. Frontiers in Endocrinology 779. (doi:10.3389/fendo.2016.00079)

Dores RM \& Lecaude S 2005 Trends in the evolution of the proopiomelanocortin gene. General and Comparative Endocrinology 142 81-93. (doi:10.1016/j.ygcen.2005.02.003)

Dores RM, Liang L, Davis P, Thomas AL \& Petko B 2016 a 60 YEARS OF POMC: melanocortin receptors: evolution of ligand selectivity 
for melanocortin peptides. Journal of Molecular Endocrinology 56 T119-T133. (doi:10.1530/JME-15-0292)

Dores RM, Thomas A, Maekawa F, Kawashima T, Sakamoto H \& Sakamoto T $2016 b$ Melanocortin receptors and MRAP expression in the chick adrenal gland: correlating mRNA expression levels and ligand sensitivity of chick melanocortin receptors expressed in CHO cells. In 11th International Symposium on Avian Endocrinology (ISAE2016), Niagara, Canada, p 60.

Dunn IC, Wilson PW, Smulders TV, Sandilands V, D'Eath RB \& Boswell T 2013 Hypothalamic agouti-related protein expression is affected by both acute and chronic experience of food restriction and re-feeding in chickens. Journal of Neuroendocrinology 25 920-928. (doi:10.1111/ jne.12088)

Dunn IC, Wilson PW, D'Eath RB \& Boswell T 2015 Hypothalamic agoutirelated peptide mRNA is elevated during natural and stress-induced anorexia. Journal of Neuroendocrinology 27 681-691. (doi:10.1111/ jne.12295)

Fong TM, Mao C, MacNeil T, Kalyani R, Smith T, Weinberg D, Tota MR \& Van der Ploeg LH 1997 ART (protein product of agouti-related transcript) as an antagonist of MC-3 and MC-4 receptors. Biochemical and Biophysical Research Communications 237 629-631. (doi:10.1006/ bbrc.1997.7200)

Forlano PM \& Cone RD 2007 Conserved neurochemical pathways involved in hypothalamic control of energy homeostasis. Journal of Comparative Neurology 505 235-248. (doi:10.1002/cne.21447)

Freeman BM \& Manning AC 1975 The response of the immature fowl to multiple injections of adrenocorticotrophic hormone. British Poultry Science 16 121-129. (doi:10.1080/00071667508416170)

Gantz I, Konda Y, Tashiro T, Shimoto Y, Miwa H, Munzert G, Watson SJ, DelValle J \& Yamada T 1993a Molecular cloning of a novel melanocortin receptor. Journal of Biological Chemistry 268 8246-8250.

Gantz I, Miwa H, Konda Y, Shimoto Y, Tashiro T, Watson SJ, DelValle J \& Yamada T $1993 b$ Molecular cloning, expression, and gene localization of a fourth melanocortin receptor. Journal of Biological Chemistry 268 15174-15179.

Gao S, Zhang J, He C, Meng F, Bu G, Zhu G, Li J \& Wang Y 2017 Molecular characterization of neuropeptide Y (NPY) receptors (Y1, Y4 and Y6) and investigation of the tissue expression of their ligands (NPY, PYY and PP) in chickens. General and Comparative Endocrinology 240 46-60. (doi:10.1016/j.ygcen.2016.09.005)

Ghamari-Langroudi M, Digby GJ, Sebag JA, Millhauser GL, Palomino R, Matthews R, Gillyard T, Panaro BL, Tough IR, Cox HM, et al. 2015 G-protein-independent coupling of MC4R to Kir7.1 in hypothalamic neurons. Nature 520 94-98. (doi:10.1038/nature14051)

Graham M, Shutter JR, Sarmiento U, Sarosi I \& Stark KL 1997 Overexpression of Agrt leads to obesity in transgenic mice. Nature Genetics 17 273-274. (doi:10.1038/ng1197-273)

Hahn TM, Breininger JF, Baskin DG \& Schwartz MW 1998 Coexpression of Agrp and NPY in fasting-activated hypothalamic neurons. Nature Neuroscience 1 271-272. (doi:10.1038/1082)

Haskell-Luevano C \& Monck EK 2001 Agouti-related protein functions as an inverse agonist at a constitutively active brain melanocortin-4 receptor. Regulatory Peptides 99 1-7. (doi:10.1016/S01670115(01)00234-8)

He C, Zhang J, Gao S, Meng F, Bu G, Li J \& Wang Y 2016 Molecular characterization of three NPY receptors (Y2, Y5 and Y7) in chickens: gene structure, tissue expression, promoter identification, and functional analysis. General and Comparative Endocrinology 236 24-34 (doi:10.1016/j.ygcen.2016.04.019)

Hen G, Yosefi S, Simchaev V, Shinder D, Hruby VJ \& Friedman-Einat M 2006 The melanocortin circuit in obese and lean strains of chicks Journal of Endocrinology 190 527-535. (doi:10.1677/joe.1.06783)

Huang G, Li J, Wang H, Lan X \& Wang Y 2014 Discovery of a novel functional leptin protein (LEP) in zebra finches: evidence for the existence of an authentic avian leptin gene predominantly expressed in the brain and pituitary. Endocrinology 155 3385-3396. (doi:10.1210/en.2014-1084)

Huszar D, Lynch CA, Fairchild-Huntress V, Dunmore JH, Fang Q, Berkemeier LR, Gu W, Kesterson RA, Boston BA, Cone RD, et al. 1997 Targeted disruption of the melanocortin-4 receptor results in obesity in mice. Cell 88 131-141. (doi:10.1016/S0092-8674(00)81865-6)

Josep Agulleiro M, Cortes R, Fernandez-Duran B, Navarro S, Guillot R, Meimaridou E, Clark AJ \& Cerda-Reverter JM 2013 Melanocortin 4 receptor becomes an ACTH receptor by coexpression of melanocortin receptor accessory protein 2. Molecular Endocrinology 27 1934-1945. (doi:10.1210/me.2013-1099)

Kawakami S, Bungo T, Ando R, Ohgushi A, Shimojo M, Masuda Y \& Furuse M 2000 Central administration of alpha-melanocyte stimulating hormone inhibits fasting- and neuropeptide Y-induced feeding in neonatal chicks. European Journal of Pharmacology 398 361-364. (doi:10.1016/S0014-2999(00)00344-7)

Kay EI, Botha R, Montgomery JM \& Mountjoy KG 2013 hMRAPa increases alphaMSH-induced hMC1R and hMC3R functional coupling and hMC4R constitutive activity. Journal of Molecular Endocrinology $\mathbf{5 0}$ 203-215. (doi:10.1530/JME-12-0221)

Krieger DT, Liotta A \& Brownstein MJ 1977 Presence of corticotropin in brain of normal and hypophysectomized rats. PNAS 74 648-652. (doi:10.1073/pnas.74.2.648)

Krude H, Biebermann H, Luck W, Horn R, Brabant G \& Gruters A 1998 Severe early-onset obesity, adrenal insufficiency and red hair pigmentation caused by POMC mutations in humans. Nature Genetics 19 155-157. (doi:10.1038/509)

Kuenzel WJ, Douglass LW \& Davison BA 1987 Robust feeding following central administration of neuropeptide Y or peptide YY in chicks, Gallus domesticus. Peptides 8 823-828. (doi:10.1016/0196-9781(87)90066-0)

Ling MK, Hotta E, Kilianova Z, Haitina T, Ringholm A, Johansson L, Gallo-Payet N, Takeuchi S \& Schioth HB 2004 The melanocortin receptor subtypes in chicken have high preference to ACTH-derived peptides. British Journal of Pharmacology 143 626-637. (doi:10.1038/ sj.bjp.0705900)

Metherell LA, Chapple JP, Cooray S, David A, Becker C, Ruschendorf F, Naville D, Begeot M, Khoo B, Nurnberg P, et al. 2005 Mutations in MRAP, encoding a new interacting partner of the ACTH receptor, cause familial glucocorticoid deficiency type 2. Nature Genetics $\mathbf{3 7}$ 166-170. (doi:10.1038/ng1501)

Morton GJ, Cummings DE, Baskin DG, Barsh GS \& Schwartz MW 2006 Central nervous system control of food intake and body weight. Nature 443 289-295. (doi:10.1038/nature05026)

Mountjoy KG, Robbins LS, Mortrud MT \& Cone RD 1992 The cloning of a family of genes that encode the melanocortin receptors. Science $\mathbf{2 5 7}$ 1248-1251. (doi:10.1126/science.1325670)

Mountjoy KG, Mortrud MT, Low MJ, Simerly RB \& Cone RD 1994 Localization of the melanocortin-4 receptor (MC4-R) in neuroendocrine and autonomic control circuits in the brain. Molecular Endocrinology 8 1298-1308. (doi:10.1210/me.8.10.1298)

Nijenhuis WA, Oosterom J \& Adan RA 2001 AgRP(83-132) acts as an inverse agonist on the human-melanocortin-4 receptor. Molecular Endocrinology 15 164-171. (doi:10.1210/me.15.1.164)

O'Donohue TL \& Dorsa DM 1982 The opiomelanotropinergic neuronal and endocrine systems. Peptides 3 353-395. (doi:10.1016/01969781(82)90098-5)

Ollmann MM, Wilson BD, Yang YK, Kerns JA, Chen Y, Gantz I \& Barsh GS 1997 Antagonism of central melanocortin receptors in vitro and in vivo by agouti-related protein. Science 278 135-138. (doi:10.1126/ science.278.5335.135)

Phillips-Singh D, Li Q, Takeuchi S, Ohkubo T, Sharp PJ \& Boswell T 2003 Fasting differentially regulates expression of agouti-related peptide, pro-opiomelanocortin, prepro-orexin, and vasoactive intestinal polypeptide mRNAs in the hypothalamus of Japanese quail. Cell and Tissue Research 313 217-225. (doi:10.1007/s00441-003-0755-8) http://joe.endocrinology-journals.org

DOI: 10.1530/JOE-17-0131
(C) 2017 Society for Endocrinology Printed in Great Britain 
Poggioli R, Vergoni AV \& Bertolini A 1986 ACTH-(1-24) and alpha-MSH antagonize feeding behavior stimulated by kappa opiate agonists. Peptides 7 843-848. (doi:10.1016/0196-9781(86)90104-X)

Qiu X, Li N, Deng X, Zhao X, Meng Q \& Wang X 2006 The single nucleotide polymorphisms of chicken melanocortin-4 receptor (MC4R) gene and their association analysis with carcass traits. Science in China Series C Life Sciences 49 560-566. (doi:10.1007/s11427-006-2029-7)

Ren J, Li Y, Xu N, Li H, Li C, Han R, Wang Y, Li Z, Kang X, Liu X, et al. 2017 Association of estradiol on expression of melanocortin receptors and their accessory proteins in the liver of chicken (Gallus gallus). General and Comparative Endocrinology 240 182-190. (doi:10.1016/j.ygcen.2016.10.012)

Resnyk CW, Carre W, Wang X, Porter TE, Simon J, Le Bihan-Duval E, Duclos MJ, Aggrey SE \& Cogburn LA 2013 Transcriptional analysis of abdominal fat in genetically fat and lean chickens reveals adipokines, lipogenic genes and a link between hemostasis and leanness. BMC Genomics 14 557. (doi:10.1186/1471-2164-14-557)

Roselli-Rehfuss L, Mountjoy KG, Robbins LS, Mortrud MT, Low MJ, Tatro JB, Entwistle ML, Simerly RB \& Cone RD 1993 Identification of a receptor for gamma melanotropin and other proopiomelanocortin peptides in the hypothalamus and limbic system. PNAS 90 8856-8860. (doi:10.1073/pnas.90.19.8856)

Rossi M, Kim MS, Morgan DG, Small CJ, Edwards CM, Sunter D, Abusnana S, Goldstone AP, Russell SH, Stanley SA, et al. 1998 A C-terminal fragment of Agouti-related protein increases feeding and antagonizes the effect of alpha-melanocyte stimulating hormone in vivo. Endocrinology 139 4428-4431. (doi:10.1210/endo.139.10.6332)

Scanes CG 2015 Pituitary gland. In Sturkie's Avian Physiology, 6th ed., pp 497-523. Ed CG Scanes. New York, NY, USA: Academic Press.

Schjolden J, Schioth HB, Larhammar D, Winberg S \& Larson ET 2009 Melanocortin peptides affect the motivation to feed in rainbow trout (Oncorhynchus mykiss). General and Comparative Endocrinology 160 134-138. (doi:10.1016/j.ygcen.2008.11.003)

Sebag JA \& Hinkle PM 2007 Melanocortin-2 receptor accessory protein MRAP forms antiparallel homodimers. PNAS 104 20244-20249. (doi:10.1073/pnas.0708916105)

Sebag JA \& Hinkle PM 2009a Opposite effects of the melanocortin-2 (MC2) receptor accessory protein MRAP on MC2 and MC5 receptor dimerization and trafficking. Journal of Biological Chemistry $\mathbf{2 8 4}$ 22641-22648. (doi:10.1074/jbc.M109.022400)

Sebag JA \& Hinkle PM $2009 b$ Regions of melanocortin 2 (MC2) receptor accessory protein necessary for dual topology and MC2 receptor trafficking and signaling. Journal of Biological Chemistry 284 610-618. (doi:10.1074/jbc.M804413200)

Sebag JA, Zhang C, Hinkle PM, Bradshaw AM \& Cone RD 2013 Developmental control of the melanocortin- 4 receptor by MRAP2 proteins in zebrafish. Science 341 278-281. (doi:10.1126/science.1232995)

Seroussi E, Cinnamon Y, Yosefi S, Genin O, Smith JG, Rafati N, Bornelov S, Andersson L \& Friedman-Einat M 2016 Identification of the longsought leptin in chicken and duck: expression pattern of the highly GC-rich avian leptin fits an autocrine/paracrine rather than endocrine function. Endocrinology 157 737-751. (doi:10.1210/en.2015-1634)

Shipp SL, Yi J, Dridi S, Gilbert ER \& Cline MA 2015 The central anorexigenic mechanism of adrenocorticotropic hormone involves the caudal hypothalamus in chicks. Neuropeptides 53 29-35. (doi:10.1016/j.npep.2015.07.005)

Shutter JR, Graham M, Kinsey AC, Scully S, Luthy R \& Stark KL 1997 Hypothalamic expression of ART, a novel gene related to agouti, is up-regulated in obese and diabetic mutant mice. Genes and Development 11 593-602. (doi:10.1101/gad.11.5.593)

Song Y \& Cone RD 2007 Creation of a genetic model of obesity in a teleost. FASEB Journal 21 2042-2049. (doi:10.1096/fj.06-7503com)
Strader AD, Schioth HB \& Buntin JD 2003 The role of the melanocortin system and the melanocortin-4 receptor in ring dove (Streptopelia risoria) feeding behavior. Brain Research 960 112-121. (doi:10.1016/ S0006-8993(02)03799-X)

Tachibana T, Sugahara K, Ohgushi A, Ando R, Kawakami S, Yoshimatsu T \& Furuse M 2001 Intracerebroventricular injection of agouti-related protein attenuates the anorexigenic effect of alpha-melanocyte stimulating hormone in neonatal chicks. Neuroscience Letters $\mathbf{3 0 5}$ 131-134. (doi:10.1016/S0304-3940(01)01827-4)

Takeuchi S \& Takahashi S 1998 Melanocortin receptor genes in the chicken - tissue distributions. General and Comparative Endocrinology 112 220-231. (doi:10.1006/gcen.1998.7167)

Takeuchi S \& Takahashi S 1999 A possible involvement of melanocortin 3 receptor in the regulation of adrenal gland function in the chicken. Biochimica et Biophysica Acta 1448 512-518. (doi:10.1016/S01674889(98)00165-7)

Takeuchi S, Kudo T \& Takahashi S 1998 Molecular cloning of the chicken melanocortin 2 (ACTH)-receptor gene. Biochimica et Biophysica Acta 1403 102-108. (doi:10.1016/S0167-4889(98)00022-6)

Takeuchi S, Teshigawara K \& Takahashi S 1999 Molecular cloning and characterization of the chicken pro-opiomelanocortin (POMC) gene. Biochimica et Biophysica Acta 1450 452-459. (doi:10.1016/S01674889(99)00046-4)

Takeuchi S, Teshigawara K \& Takahashi S 2000 Widespread expression of Agouti-related protein (AGRP) in the chicken: a possible involvement of AGRP in regulating peripheral melanocortin systems in the chicken. Biochimica et Biophysica Acta 1496 261-269. (doi:10.1016/ S0167-4889(00)00022-7)

Vergoni AV, Poggioli R \& Bertolini A 1986 Corticotropin inhibits food intake in rats. Neuropeptides 7 153-158. (doi:10.1016/01434179(86)90091-0)

Wang Y, Li J, Wang CY, Kwok AH \& Leung FC 2007 Identification of the endogenous ligands for chicken growth hormone-releasing hormone (GHRH) receptor: evidence for a separate gene encoding GHRH in submammalian vertebrates. Endocrinology 148 2405-2416. (doi:10.1210/en.2006-1013)

Wang Y, Meng F, Zhong Y, Huang G \& Li J 2012 Discovery of a novel glucagon-like peptide (GCGL) and its receptor (GCGLR) in chickens: evidence for the existence of GCGL and GCGLR genes in nonmammalian vertebrates. Endocrinology 153 5247-5260. (doi:10.1210/en.2012-1586)

Wang ZQ, Huang JS, Zhou JH, Shi L, Jiang XF \& Tao YX 2016 Pharmacologic analyses of four chicken melanocortin-4 receptor mutations. Domestic Animal Endocrinology 54 68-75. (doi:10.1016/j. domaniend.2015.06.003)

Xu Z, Ji C, Zhang Y, Zhang Z, Nie Q, Xu J, Zhang D \& Zhang X 2016 Combination analysis of genome-wide association and transcriptome sequencing of residual feed intake in quality chickens. BMC Genomics 17 594. (doi:10.1186/s12864-016-2861-5)

Yaswen L, Diehl N, Brennan MB \& Hochgeschwender U 1999 Obesity in the mouse model of pro-opiomelanocortin deficiency responds to peripheral melanocortin. Nature Medicine 5 1066-1070. (doi:10.1038/12506)

Yi J, Gilbert ER, Siegel PB \& Cline MA 2015 Fed and fasted chicks from lines divergently selected for low or high body weight have differential hypothalamic appetite-associated factor mRNA expression profiles. Behavioural Brain Research 286 58-63. (doi:10.1016/j. bbr.2015.02.008)

Zhang C, Forlano PM \& Cone RD 2012 AgRP and POMC neurons are hypophysiotropic and coordinately regulate multiple endocrine axes in a larval teleost. Cell Metabolism 15 256-264. (doi:10.1016/j. cmet.2011.12.014)

Received in final form 10 May 2017

Accepted 15 May 2017

Accepted Preprint published online 16 May 2017 http://joe.endocrinology-journals.org

DOI: 10.1530/JOE-17-0131 (c) 2017 Society for Endocrinology Printed in Great Britain
Published by Bioscientifica Ltd. 